\title{
Microwave snow emission modeling uncertainties in boreal and subarctic environments
}

\author{
Alexandre Roy ${ }^{1,2}$, Alain Royer ${ }^{1,2}$, Olivier St-Jean-Rondeau ${ }^{1,2}$, Benoit Montpetit ${ }^{1}$, Ghislain Picard ${ }^{3}$, Alex Mavrovic ${ }^{1}$, \\ Nicolas Marchand ${ }^{1,2,3}$, and Alexandre Langlois ${ }^{1,2}$ \\ ${ }^{1}$ Centre d'Applications et de Recherches en Télédétection (CARTEL), Université de Sherbrooke, \\ 2500 boul. Université, Sherbrooke, J1K 2R1, QC, Canada \\ ${ }^{2}$ Centre d'études Nordiques, Québec, Canada \\ ${ }^{3}$ Université Grenoble Alpes - CNRS, LGGE UMR5183, 38041 Grenoble, France
}

Correspondence to: Alexandre Roy (alexandre.r.roy@usherbrooke.ca)

Received: 15 September 2015 - Published in The Cryosphere Discuss.: 27 October 2015

Revised: 29 February 2016 - Accepted: 2 March 2016 - Published: 16 March 2016

\begin{abstract}
This study aims to better understand and quantify the uncertainties in microwave snow emission models using the Dense Media Radiative Theory Multi-Layer model (DMRT-ML) with in situ measurements of snow properties. We use surface-based radiometric measurements at 10.67, 19 and $37 \mathrm{GHz}$ in boreal forest and subarctic environments and a new in situ data set of measurements of snow properties (profiles of density, snow grain size and temperature, soil characterization and ice lens detection) acquired in the James Bay and Umiujaq regions of Northern Québec, Canada. A snow excavation experiment - where snow was removed from the ground to measure the microwave emission of bare frozen ground - shows that small-scale spatial variability (less than $1 \mathrm{~km}$ ) in the emission of frozen soil is small. Hence, in our case of boreal organic soil, variability in the emission of frozen soil has a small effect on snow-covered brightness temperature $\left(T_{\mathrm{B}}\right)$. Grain size and density measurement errors can explain the errors at $37 \mathrm{GHz}$, while the sensitivity of $T_{\mathrm{B}}$ at $19 \mathrm{GHz}$ to snow increases during the winter because of the snow grain growth that leads to scattering. Furthermore, the inclusion of observed ice lenses in DMRT-ML leads to significant improvements in the simulations at horizontal polarization (H-pol) for the three frequencies (up to $20 \mathrm{~K}$ of root mean square error). However, representation of the spatial variability of $T_{\mathrm{B}}$ remains poor at 10.67 and $19 \mathrm{GHz}$ at $\mathrm{H}$-pol given the spatial variability of ice lens characteristics and the difficulty in simulating snowpack stratigraphy related to the snow crust. The results also show that, in our study with the given forest characteristics, forest emission reflected by the
\end{abstract}

snow-covered surface can increase the $T_{\mathrm{B}}$ up to $40 \mathrm{~K}$. The forest contribution varies with vegetation characteristics and a relationship between the downwelling contribution of vegetation and the proportion of pixels occupied by vegetation (trees) in fisheye pictures was found. We perform a comprehensive analysis of the components that contribute to the snow-covered microwave signal, which will help to develop DMRT-ML and to improve the required field measurements. The analysis shows that a better consideration of ice lenses and snow crusts is essential to improve $T_{\mathrm{B}}$ simulations in boreal forest and subarctic environments.

\section{Introduction}

Seasonal snow cover plays an important role in the surface energy balance (Armstrong and Brun, 2008). Snow, with its low thermal conductivity, has an insulating effect on soils, which can greatly influence vegetation (Liston et al., 2002) and the development of active layers in permafrost (Gouttevin et al., 2012; Schuur et al., 2013). Snow water equivalent (SWE) is also a key variable in the high-latitude water cycle (Déry et al., 2009) and is important for dam management and hydroelectricity production (Roy et al., 2010). Conventional in situ observations, such as from meteorological stations, are often inadequate to monitor seasonal snow evolution given the sparse distribution of stations in northern regions. Furthermore, point measurements are subject to local scale variability and may not represent the prevailing re- 
gional conditions. For these reasons, monitoring SWE from satellite passive microwave (PMW) observations has been the subject of numerous studies for nearly 3 decades (e.g., Chang et al., 1987; Goodison et al., 1986; Derksen, 2008). The PMW observations are sensitive to SWE but also have the advantage of providing observations at a synoptic scale in any weather condition: images are available at least twice a day for the northern regions. However, estimation of SWE is not straightforward and existing empirical algorithms based on linear relationships between SWE and spectral $T_{\mathrm{B}}$ are often inaccurate due to seasonal snow grain metamorphism (Rosenfeld and Grody, 2000). Vegetation contributions are also an important factor with large interannual variability (Roy et al., 2015), which is not captured by these algorithms. Hence, radiative transfer models including microwave snow emission models (MSEM) can be used to take into account the different contributions to the microwave signal and the interannual variability of critical geophysical parameters. The GlobSnow2 SWE retrieval algorithm (Takala et al., 2011) uses an assimilation scheme combining PMW observations constrained with kriged measurements of snow depth from meteorological stations. This method, however, has some limitations in remote areas where snow measurements are sparse, thus highlighting the need to improve MSEM performance in such a way that SWE retrievals can be achieved without in situ observations (Hancock et al., 2013).

At the satellite scale, PMW observations generally have a coarse spatial resolution (more than $10 \mathrm{~km} \times 10 \mathrm{~km}$ ). Nevertheless, spatial heterogeneity within PMW pixels becomes a limitation for the development and validation of MSEM because contributions from snow, vegetation and lakes are difficult to decouple. Therefore, surface-based radiometers (SBRs) are used to better understand and isolate the contribution of snow-covered surfaces. However, independently of MSEM used and seasonal snow type, the comparison between simulated $T_{\mathrm{B}}$ and SBR observations leads to errors on the order of $10 \mathrm{~K}$ (Roy et al., 2013; Montpetit et al., 2013; Derksen et al., 2012; Kontu and Pulliainen, 2010; Lemmetyinen et al., 2010, 2015; Durand et al., 2008). From SBR measurements, these errors can be explained by (1) MSEM physical simplification (Tedesco and Kim, 2006) and (2) smallscale variability and uncertainty in measurements of geophysical parameters.

Hence, this paper aims to better quantify the relative importance of different geophysical parameters and small-scale spatial variability when simulating microwave $T_{\mathrm{B}}$ with the Dense Media Radiative Theory Multi-Layer model (DMRTML; Picard et al., 2013). The study is based on a new and unique database including SBR measurements at three microwave frequencies $(37,19$ and $10.67 \mathrm{GHz})$ in boreal and subarctic environments. The study assesses a wide range of contributions that could lead to uncertainties in ground-based microwave snow emission modeling: snow grains, snow density, soil roughness, ice lenses (ILs) and vegetation. More specifically, the objectives of the study are

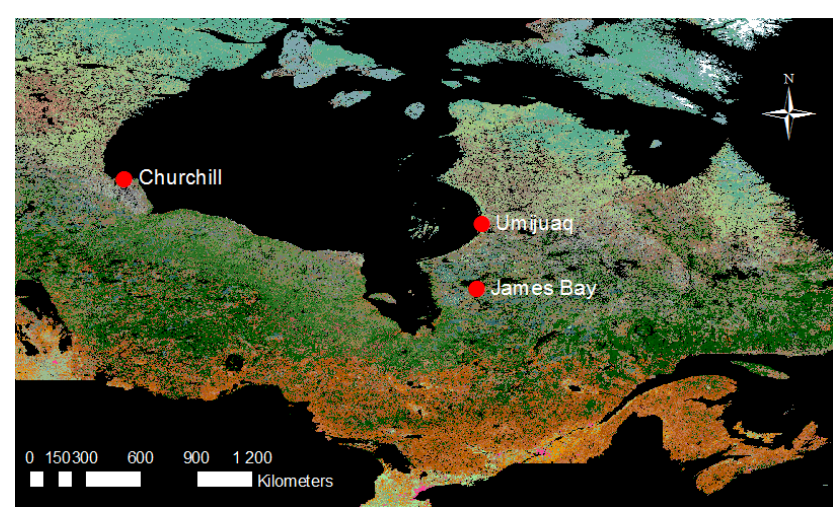

Figure 1. Location of field campaigns. Background: Land Cover of Canada (Latifovic et al., 2004).

1. to validate the snow emission modeling, including recent improvements accounting for ice lenses (Montpetit et al., 2013) and snow density in the $367-550 \mathrm{~kg} \mathrm{~m}^{-3}$ range (Dierking et al., 2012);

2. to evaluate the different contributions to modeling uncertainty (snow grains, snow density, ice lenses, soil and vegetation measurements);

3. to quantify the sensitivity of simulated $T_{\mathrm{B}}$ to the measurement accuracy.

\section{Method}

\subsection{Sites and data}

Surface-based radiometer observations were acquired during the 2010 field campaign at the Churchill Northern Studies Center (Northern Manitoba) (see Roy et al., 2013, for a detailed description of the field campaign) and during four subsequent field campaigns in Northern Québec, Canada: three in James Bay $\left(53^{\circ} 26^{\prime} \mathrm{N}, 76^{\circ} 46^{\prime} \mathrm{W}\right.$; $186 \mathrm{~m}$ a.s.l) in winter 2013 and one campaign in Umiujaq $\left(56^{\circ} 33^{\prime} \mathrm{N}, 76^{\circ} 30^{\prime} \mathrm{W}\right.$; $74 \mathrm{~m}$ a.s.l) in winter 2014 (Fig. 1). All these campaign allow covering a wide range of environmental conditions from dense boreal forest to open tundra for a total of 51 snow pits (excluding the Churchill snow pits).

$T_{\mathrm{B}}$ measurements were acquired at 37,19 and $10.67 \mathrm{GHz}$ in both vertical (V-pol) and horizontal (H-pol) polarizations at a height of approximately $1.5 \mathrm{~m}$ above the ground and at an angle of $55^{\circ}$ with the PR-series SBRs from Radiometrics Corporation (Langlois, 2015) (hereinafter, the $10.67 \mathrm{GHz}$ SBR is noted $11 \mathrm{GHz}$ for simplicity). With a beam width of $6^{\circ}$ for 37 and $19 \mathrm{GHz}$ SBR, the footprint of the measurements at the snow surface was approximately $0.6 \mathrm{~m} \times 0.6 \mathrm{~m}$. The $11 \mathrm{GHz}$ beam width is $8^{\circ}$ with a footprint of about $0.8 \times 0.8 \mathrm{~m}$. In the worst case, the measurement error for the calibration target was estimated at $2 \mathrm{~K}$. The radiometers were 
Table 1. Average snow property values with standard deviation (in parentheses) at James Bay (JB) sites in January. Values are provided for snow depth $\left(\mathrm{SD}\right.$ m), mean snowpack temperature $\left(T_{\text {snow }}\right)$, bulk density $\left(\rho_{\text {snow }}\right)$, mean optical radius $\left(R_{\text {opt }}\right)$, soil/snow temperature $\left(T_{\text {soil }}\right)$ and number of observed ice lenses (ILs); SP is snow pit and "bridging" (B) indicates the presence of a snow layer with a density within the bridging ice fraction limits (see Sect. 2.2.2).

\begin{tabular}{|c|c|c|c|c|c|c|c|c|}
\hline SP & Type & $\begin{array}{l}\text { SD } \\
(\mathrm{cm})\end{array}$ & $\begin{array}{l}T_{\text {snow }} \\
(\mathrm{K})\end{array}$ & $\begin{array}{l}\rho_{\text {snow }} \\
\left(\mathrm{kg} \mathrm{m}^{-3}\right)\end{array}$ & $\begin{array}{l}R_{\mathrm{opt}} \\
(\mathrm{mm})\end{array}$ & $\begin{array}{l}T_{\text {soil }} \\
(\mathrm{K})\end{array}$ & IL $\quad$ B & Date \\
\hline $\mathrm{JB}_{\mathrm{Jan}-1}$ & Forest & 37 & $259.9(4.8)$ & $305.6(227.4)$ & $0.19(0.09)$ & 272.3 & 1 & 7 Jan 2013 \\
\hline $\mathrm{JB}_{\mathrm{Jan}}-2$ & clearing & 43 & $265.3(3.4)$ & $274.5(224.4)$ & $0.15(0.07)$ & 272.0 & 1 & 8 Jan 2013 \\
\hline $\mathrm{JB}_{\mathrm{Jan}}-3$ & organic soil & 48 & $264.8(4.2)$ & $301.0(192.7)$ & $0.20(0.10)$ & 272.6 & 1 & 8 Jan 2013 \\
\hline $\mathrm{JB}_{\mathrm{Jan}-4}$ & & 48 & $264.9(3.6)$ & $275.2(202.9)$ & $0.17(0.09)$ & 272.3 & 1 & 8 Jan 2013 \\
\hline $\mathrm{JB}_{\mathrm{Jan}}-5$ & & 62 & $267.5(1.8)$ & $273.0(186.3)$ & $0.15(0.08)$ & 272.4 & 1 & 11 Jan 2013 \\
\hline $\mathrm{JB}_{\mathrm{Jan}}-6.1$ & Old gravel pit & 51 & $266.8(2.4)$ & $284.9(198.1)$ & $0.17(0.08)$ & 271.5 & 1 & 9 Jan 2013 \\
\hline $\mathrm{JB}_{\mathrm{Jan}}-6.2$ & Mineral soil & 52 & $267.4(2.4)$ & $300.1(194.0)$ & $0.18(0.08)$ & 271.5 & 1 & 9 Jan 2013 \\
\hline $\mathrm{JB}_{\mathrm{Jan}}-6.3$ & $\mathrm{JB}_{\text {Jan-transect }}$ & 43 & $266.5(1.4)$ & $281.5(208.8)$ & $0.17(0.08)$ & 271.3 & 1 & 9 Jan 2013 \\
\hline $\mathrm{JB}_{\mathrm{Jan}}-6.4$ & & 45 & $268.0(2.3)$ & $273.9(211.8)$ & $0.18(0.09)$ & 272.1 & 1 & 9 Jan 2013 \\
\hline $\mathrm{JB}_{\mathrm{Jan}}-6.5$ & & 53 & $267.2(2.6)$ & $299.2(185.2)$ & $0.16(0.09)$ & 272.6 & 1 & 9 Jan 2013 \\
\hline $\mathrm{JB}_{\mathrm{Jan}}-6.6$ & & 51 & $267.0(2.2)$ & 285.8 (197.7) & $0.18(009)$ & 272.0 & 1 & 9 Jan 2013 \\
\hline $\mathrm{JB}_{\mathrm{Jan}}-6.7$ & & 47 & $267.2(2.0)$ & $343.7(264.1)$ & $0.16(0.10)$ & 271.6 & 2 & 9 Jan 2013 \\
\hline $\mathrm{JB}_{\mathrm{Jan}}-6.8$ & & 47 & $267.5(2.3)$ & 331.7 (269.9) & $0.14(0.08)$ & 271.8 & 2 & 9 Jan 2013 \\
\hline $\mathrm{JB}_{\mathrm{Jan}}-6.9$ & & 46 & $267.1(1.8)$ & $335.0(267.9)$ & $0.16(0.10)$ & 271.1 & 2 & 9 Jan 2013 \\
\hline $\mathrm{JB}_{\mathrm{Jan}}-6.10$ & & 45 & $266.7(1.5)$ & $272.4(210.4)$ & $0.14(0.07)$ & 270.3 & 1 & 9 Jan 2013 \\
\hline $\mathrm{JB}_{\mathrm{Jan}}-6.11$ & & 40 & $266.8(1.2)$ & $290.8(216.6)$ & $0.17(0.10)$ & 269.6 & 1 & 9 Jan 2013 \\
\hline
\end{tabular}

calibrated before and after each field campaign using ambient (black body) and cold (liquid nitrogen) targets.

Within the footprint of every SBR observation, profiles of snow temperature, snow density $\left(\rho_{\text {snow }}\right.$ in $\left.\mathrm{kg} \mathrm{m}^{-3}\right)$ and specific surface area (SSA in $\mathrm{m}^{2} \mathrm{~kg}^{-1}$ ) were taken at a vertical resolution between 3 and $5 \mathrm{~cm}$. Visual stratigraphy assessment of the main snow layers/features, including ice lenses, was conducted. The density was measured using a $185 \mathrm{~cm}^{3}$ density cutter, and samples were weighed with a $100 \mathrm{~g}$ Pesola light series scale with an accuracy of $0.5 \mathrm{~g}$. The snow temperature and soil temperature were measured with a Traceable 2000 digital temperature probe $\left( \pm 0.1^{\circ} \mathrm{C}\right)$. The SSA was measured with the shortwave infrared integrating sphere (IRIS) system (Montpetit et al., 2012) at the James Bay site and using the Dual Frequency Integrating Sphere for Snow SSA instrument (DUFISSS; Gallet et al., 2009) in Umiujaq. Both instruments exploit the relationship between the shortwave infrared snow reflectance and the SSA (Kokhanovsky and Zege, 2004) based on the principle described in Gallet et al. (2009). From SSA measurements, the optical radius of the snow grain $\left(R_{\mathrm{opt}}\right)$ was calculated by

$R_{\mathrm{opt}}=\frac{3}{\rho_{\text {ice SSA }}}$,

where $\rho_{\text {ice }}$ is the ice density $=917 \mathrm{~kg} \mathrm{~m}^{-3}$. The SSA is one of the most robust and objective approaches to measure a parameter related to the size of snow grains in the field. The error for SSA measurements was estimated to be $12 \%$ (Gallet et al., 2009).

\subsubsection{James Bay, Québec, Canada}

Three intensive measurement periods were conducted during the 2013 winter season in the James Bay area, Québec (8-12 January: JB Jan; 12-17 February: $\mathrm{JB}_{\mathrm{Feb}}$; 19-23 March: $\mathrm{JB}_{\mathrm{Mar}}$; Tables 1, 2 and 3). The sites were in a typical boreal forest environment, but most of the measurements were conducted in clearings with minimal influence of the environment (topography, vegetation) on the measured $T_{\mathrm{B}}$. However, 15 measurements, spanning across the three campaigns, were conducted in forested areas and were treated separately to specifically investigate the contribution of vegetation on the ground-based measurements (Table 4). Several snow excavation experiments (denoted SEex) were also conducted where snow was removed to measure frozen ground emission. During SEex, large snow pits were dug (about $3 \mathrm{~m} \times 3 \mathrm{~m}$ wide) and the snow walls removed to eliminate snow wall emission reflected on the ground. At all sites, the soil (described below) was frozen at least to a depth of $10 \mathrm{~cm}$.

During the $\mathrm{JB}_{\mathrm{Jan}}$ campaign, 16 open-area sites were measured where the mean $\rho_{\text {snow }}$ (weighted by snow layers thickness excluding ice lenses) of all snow pits was $218.3 \mathrm{~kg} \mathrm{~m}^{-3}$ and the mean $R_{\text {opt }}$ (weighted by snow layers thickness excluding ice lenses) was $0.17 \mathrm{~mm}$ (Table 1). Snow pits JB $\mathrm{Jan}_{-}$ 1 to $\mathrm{JB}_{\mathrm{Jan}}-5$ were located in forest clearings where the soil composition mainly consisted of organic matter. On 9 January, a transect of 11 snow pits $\left(\mathrm{JB}_{\mathrm{Jan}}-6.1\right.$ to $\mathrm{JB}_{\mathrm{Jan}}-6.11$, each separated by $3 \mathrm{~m}$ ) was conducted in an old gravel pit (mostly mineral soil). Five SEex were also conducted in the 
Table 2. Same as Table 1 but for James Bay sites in February $\left(\mathrm{JB}_{\mathrm{Feb}}\right)$.

\begin{tabular}{|c|c|c|c|c|c|c|c|c|c|}
\hline SP & Type & $\begin{array}{l}\mathrm{SD} \\
(\mathrm{cm})\end{array}$ & $\begin{array}{l}T_{\text {snow }} \\
(\mathrm{K})\end{array}$ & $\begin{array}{l}\rho_{\text {snow }} \\
\left(\mathrm{kg} \mathrm{m}^{-3}\right)\end{array}$ & $\begin{array}{l}R_{\mathrm{opt}} \\
(\mathrm{mm})\end{array}$ & $\begin{array}{l}T_{\text {soil }} \\
(\mathrm{K})\end{array}$ & IL & B & Date \\
\hline $\mathrm{JB}_{\mathrm{Feb}^{-1}}$ & Forest & 62 & $266.9(2.3)$ & $290.9(177.6)$ & $0.21(0.12)$ & 272.8 & 1 & & 12 Feb 2013 \\
\hline $\mathrm{JB}_{\mathrm{Feb}}-2$ & clearing & 66 & $265.8(5.0)$ & $245.1(185.2)$ & $0.24(0.10)$ & 273.1 & 1 & & 13 Feb 2013 \\
\hline $\mathrm{JB}_{\mathrm{Feb}}-3.1$ & organic & 66 & $265.3(3.2)$ & $301.0(188.7)$ & $0.18(0.09)$ & 270.8 & 1 & $\mathrm{x}$ & 15 Feb 2013 \\
\hline $\mathrm{JB}_{\mathrm{Feb}}-3.2$ & soil & 66 & $265.6(3.3)$ & $264.8(184.8)$ & $0.18(0.09)$ & 270.5 & 1 & & 15 Feb 2013 \\
\hline $\mathrm{JB}_{\mathrm{Feb}}-3.3$ & & 65 & $265.9(3.0)$ & $276.8(181.2)$ & $0.11(0.05)$ & 270.5 & 1 & & 15 Feb 2013 \\
\hline $\mathrm{JB}_{\mathrm{Feb}}-3.4$ & & 68 & $266.6(2.6)$ & $276.1(181.0)$ & $0.17(0.09)$ & 271.3 & 1 & & 15 Feb 2013 \\
\hline $\mathrm{JB}_{\mathrm{Feb}}-3.5$ & & 65 & $264.0(4.0)$ & $282.9(182.6)$ & $0.17(0.10)$ & 271.0 & 1 & $\mathrm{x}$ & 15 Feb 2013 \\
\hline $\mathrm{JB}_{\mathrm{Feb}^{-3}}-6$ & & 65 & $266.5(4.7)$ & $271.9(185.4)$ & $0.20(0.11)$ & 271.3 & 1 & & 15 Feb 2013 \\
\hline $\mathrm{JB}_{\mathrm{Feb}}-3.7$ & & 64 & $266.0(3.2)$ & $258.3(187.5)$ & $0.18(0.11)$ & 270.8 & 1 & & 15 Feb 2013 \\
\hline
\end{tabular}

$30 \mathrm{~m}$ transect. One to two ice lenses of about 0.5 to $1 \mathrm{~cm}$ were observed in all snow pits, buried at depths of 10 and $30 \mathrm{~cm}$.

Nine snow pits were dug during the February campaign (Table 2), with a mean $\rho_{\text {snow }}$ of $225.2 \mathrm{~kg} \mathrm{~m}^{-3}$ and a mean $R_{\text {opt }}$ of $0.18 \mathrm{~mm}$. All snow pits were conducted in clearings with frozen organic soil. On 15 February, for a transect of seven snow pits, a complete set of measurements was taken for each snow pit. An ice lens at a depth of $30 \mathrm{~cm}$ was observed at each snow pit. In addition to snow pit measurements, two SEex were conducted in the transect and two others in $\mathrm{JB}_{\mathrm{Feb}}-1$ and $\mathrm{JB}_{\mathrm{Feb}}-2$.

During the March campaign, five snow pits with a mean $\rho_{\text {snow }}$ of $278 \mathrm{~kg} \mathrm{~m}^{-3}$ and mean $R_{\text {opt }}$ of $0.26 \mathrm{~mm}$ were dug (Table 3$)$. There is a clear increase $(70 \%)$ of grain size in March, linked to a strong temperature gradient metamorphism regime typical of such environments. On 22 March, a transect of three snow pits was conducted in a clearing with frozen organic soil.

Measurements were also conducted in a forested area (Table 4), where the emission of the trees that is reflected on the ground contributes to the measured $T_{\mathrm{B}}$ (Roy et al., 2012). For these reasons, these snow pits were treated separately and used to better understand the influence of tree emission on ground-based radiometric measurements. On 10 January, a transect of eight snow pits was conducted in a forested area as well as transects of three snow pits on 14 February and 21 March. In addition to the usual snow pit observations, fisheye pictures (Fig. 2) were taken during the January and February campaigns to quantify vegetation density. The pictures were binarized to distinguish sky pixels from tree pixels allowing the estimation of the proportion of pixels (fraction) occupied by vegetation $\left(\chi_{\mathrm{veg}}\right)$.

\subsubsection{Umiujaq}

An intensive measurement campaign was conducted in January 2014 (21-28 January) in the region of Umiujaq. All the measurements were conducted in a tundra environment except for the Umi-3 site, which was located in a clearing (Table 5). The tundra sites were characterized by typical dense

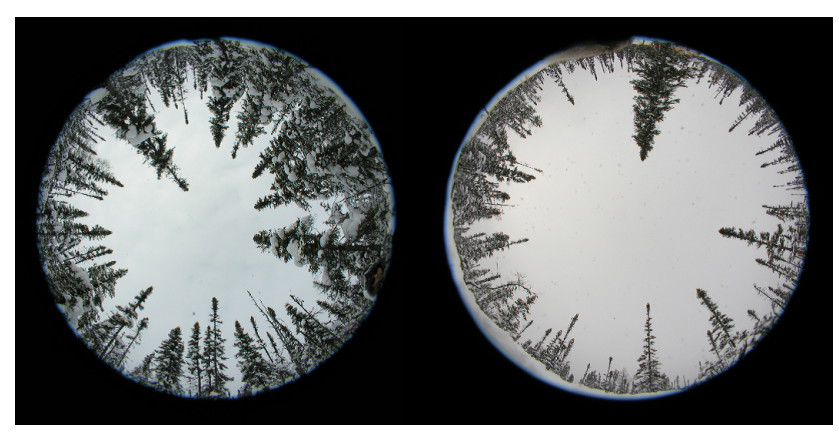

Figure 2. Fisheye pictures for $\mathrm{JB}_{\mathrm{veg}}-3.3$ (left) and $\mathrm{JB}_{\mathrm{veg}}-2.2$ (right) sites, showing the sky view proportion around the SBR site measurements.

snow drift layers near the surface that fall into the bridging limits of 0.4 and 0.6 for the ice fraction as defined by Dierking et al. (2012) (see Sect. 2.2.2). Furthermore, one to two ice lenses were observed at the UMI-1, UMI-2 and UMI-4 sites.

\subsection{Models}

The study uses the DMRT-ML model to simulate the microwave emission of snow-covered surfaces (Brucker et al., 2011; Picard et al., 2013). It is a multilayer electromagnetic model based on the DMRT theory (Tsang et al., 2001). The theory assumes that a snow layer is composed of ice spheres where the effective permittivity is calculated using the firstorder quasi-crystalline approximation and the Percus-Yevick approximation. The propagation of energy between the different layers is calculated with the discrete ordinate radiative transfer (DISORT) method as described in Jin et al. (1994). In this paper, the propagation of electromagnetic radiation was calculated for 64 streams.

The snow pit measurements $\left(\rho_{\text {snow }}, T_{\text {snow }}, T_{\text {soil }}\right.$ and $\left.R_{\text {opt }}\right)$ were integrated as input to the model to simulate snow microwave emission. However, it was shown in previous studies (Brucker et al., 2011; Roy et al., 2013; Picard et al., 2014) that using $R_{\text {opt }}$ was inadequate as input to DMRT-ML. As 
Table 3. Same as Table 1 but for James Bay sites in March ( $\left.\mathrm{JB}_{\mathrm{Mar}}\right)$.

\begin{tabular}{llllllllll}
\hline $\mathrm{SP}$ & Type & $\begin{array}{l}\mathrm{SD} \\
(\mathrm{cm})\end{array}$ & $\begin{array}{l}T_{\text {snow }} \\
(\mathrm{K})\end{array}$ & $\begin{array}{l}\rho_{\text {snow }} \\
\left(\mathrm{kg} \mathrm{m}^{-3}\right)\end{array}$ & $\begin{array}{l}R_{\text {opt }} \\
(\mathrm{mm})\end{array}$ & $\begin{array}{l}T_{\text {soil }} \\
(\mathrm{K})\end{array}$ & IL & B Date \\
\hline $\mathrm{JB}_{\mathrm{Mar}-1}$ & Forest clearing & 83 & $268.2(3.2)$ & $296.8(151.6)$ & $0.25(0.10)$ & 272.0 & 1 & $19 \mathrm{Mar} 2013$ \\
$\mathrm{JB}_{\mathrm{Mar}}-2$ & organic soil & 67 & $267.5(2.4)$ & $265.2(38.2)$ & $0.25(0.07)$ & 270.9 & 1 & $20 \mathrm{Mar} 2013$ \\
\hline $\mathrm{JB}_{\mathrm{Mar}-3.1}$ & Transect in forest & 63 & $269.3(0.8)$ & $311.4(166.7)$ & $0.28(0.11)$ & 270.5 & 1 & $22 \mathrm{Mar} 2013$ \\
$\mathrm{JB}_{\mathrm{Mar}-3.2}$ & clearing organic soil & 69 & $271.0(1.0)$ & $342.9(151.4)$ & $0.26(0.09)$ & 272.5 & 1 & $22 \mathrm{Mar} 2013$ \\
$\mathrm{JB}_{\mathrm{Mar}}-3.3$ & & 67 & $270.9(0.8)$ & $334.6(153.5)$ & $0.25(0.10)$ & 272.1 & 1 & $22 \mathrm{Mar} 2013$ \\
\hline
\end{tabular}

Table 4. Same as Table 1 but for James Bay sites, all in forested areas ( $\left.\mathrm{JB}_{\mathrm{veg}}\right)$.

\begin{tabular}{|c|c|c|c|c|c|c|c|c|}
\hline SP & Type & $\begin{array}{l}\mathrm{SD} \\
(\mathrm{cm})\end{array}$ & $\begin{array}{l}T_{\text {snow }} \\
(\mathrm{K})\end{array}$ & $\begin{array}{l}\rho_{\text {snow }} \\
\left(\mathrm{kg} \mathrm{m}^{-3}\right)\end{array}$ & $\begin{array}{l}R_{\mathrm{Opt}} \\
(\mathrm{mm})\end{array}$ & $\begin{array}{l}T_{\text {soil }} \\
(\mathrm{K})\end{array}$ & IL & Date \\
\hline $\mathrm{JB}_{\mathrm{veg}}-1$ & & 62 & $267.6(1.8)$ & 270.9 (179.7) & $0.14(0.08)$ & 272.4 & 1 & 11 Jan 2013 \\
\hline $\mathrm{JB}_{\mathrm{veg}}-2.1$ & First transect of $30 \mathrm{~m}$ & 64 & $267.4(2.7)$ & $249.1(178.9)$ & $0.18(0.09)$ & 273.3 & 1 & 10 Jan 2013 \\
\hline $\mathrm{JB}_{\mathrm{veg}}-2.2$ & & 67 & $269.0(2.3)$ & $260.8(183.7)$ & $0.15(0.09)$ & 273.3 & 1 & 10 Jan 2013 \\
\hline $\mathrm{JB}_{\mathrm{veg}}-2.3$ & & 60 & $268.3(3.1)$ & $255.1(194.5)$ & $0.16(0.09)$ & 273.4 & 1 & 10 Jan 2013 \\
\hline $\mathrm{JB}_{\mathrm{veg}}-2.4$ & & 60 & $267.6(2.1)$ & $247.4(185.1)$ & $0.19(0.10)$ & 272.4 & 1 & 10 Jan 2013 \\
\hline $\mathrm{JB}_{\mathrm{veg}}-2.5$ & & 65 & $267.1(2.5)$ & $250.6(186.2)$ & $0.15(0.08)$ & 272.8 & 1 & 10 Jan 2013 \\
\hline $\mathrm{JB}_{\mathrm{veg}}-2.6$ & & 60 & $266.3(2.0)$ & $249.7(196.3)$ & $0.15(0.08)$ & 271.9 & 1 & 10 Jan 2013 \\
\hline $\mathrm{JB}_{\mathrm{veg}}-2.7$ & & 56 & $268.4(2.5)$ & $257.8(196.8)$ & $0.15(0.09)$ & 272.9 & 1 & 10 Jan 2013 \\
\hline $\mathrm{JB}_{\mathrm{veg}}-2.8$ & & 68 & $268.1(2.9)$ & $255.0(184.1)$ & $0.14(0.08)$ & 273.1 & 1 & 10 Jan 2013 \\
\hline $\mathrm{JB}_{\text {veg }}-3.1$ & Second transect of $6 \mathrm{~m}$ & 78 & $267.0(2.8)$ & $302.0(209.3)$ & $0.19(0.10)$ & 272.4 & 2 & 14 Feb 2013 \\
\hline $\mathrm{JB}_{\mathrm{veg}}-3.2$ & & 78 & $267.4(2.4)$ & $288.9(216.1)$ & $0.19(0.10)$ & 272.6 & 2 & 14 Feb 2013 \\
\hline $\mathrm{JB}_{\text {veg }}-3.3$ & & 75 & $267.5(2.2)$ & $297.3(221.0)$ & $0.19(0.12)$ & 272.4 & 1 & 14 Feb 2013 \\
\hline $\mathrm{JB}_{\mathrm{veg}}-4.1$ & Third transect of $6 \mathrm{~m}$ & 88 & $268.1(1.5)$ & $362.0(214.6)$ & $0.20(0.11)$ & 271.9 & 3 & 21 Mar 2013 \\
\hline $\mathrm{JB}_{\text {veg }}-4.2$ & & 88 & $269.9(1.5)$ & $363.7(211.5)$ & $0.22(0.12)$ & 272.9 & 3 & 21 Mar 2013 \\
\hline $\mathrm{JB}_{\mathrm{veg}}-4.3$ & & 87 & $271.5(1.0)$ & $365.2(206.2)$ & $0.28(0.12)$ & 272.9 & 3 & 21 Mar 2013 \\
\hline
\end{tabular}

such, a scaling factor of $\varphi=3.3$ assuming non-sticky snow grains from Roy et al. (2013) for the seasonal snowpack is thus applied to get an effective radius in the microwave range $\left(R_{\text {eff }}\right)$ :

$R_{\mathrm{eff}}=R_{\mathrm{opt}} \cdot \varphi$

Roy et al. (2013) shows that the need for a scaling factor in DMRT-ML could be related to the grain size distribution of snow and the stickiness between grains, which leads to an increase of the $R_{\text {eff }}$.

The atmospheric downwelling $T_{\mathrm{B}}$ that is reflected by the snow surface to the radiometer was modeled using the millimeter-wave propagation model (Liebe et al., 1989) implemented in the Helsinki University of Technology (HUT) snow emission model (Pulliainen al., 1999). The atmospheric model was driven with the air temperature and air moisture of the atmospheric layer above the surface from the 29 North American Regional Reanalysis (Mesinger et al., 2006) atmospheric layers.

\subsubsection{Ice lenses}

The microwave signal is very sensitive to ice lens formation within a snowpack at H-pol (Montpetit et al., 2013; Rees et al., 2010; Lemmetyinen et al., 2010). To simulate the ice lenses present in this study's database (see Tables 1-5) using DMRT-ML, snow layers with a high density of $900 \mathrm{~kg} \mathrm{~m}^{-3}$ close to the density of pure ice $\left(917 \mathrm{~kg} \mathrm{~m}^{-3}\right)$ and a null snow grain size were integrated into the snowpack input file where ice lenses were observed. The value of $900 \mathrm{~kg} \mathrm{~m}^{-3}$ was chosen because only pure ice lenses were observed. To keep the same total snow depth, the adjoining layers were adjusted by removing $0.5 \mathrm{~cm}$ of the layer above and below the ice layer. However, an analysis of the effect of ice lens density on $T_{\mathrm{B}}$ simulations will be conducted in Sect. 3.2.4. Because coherency (Mätzler, 1987) is neglected in DMRT-ML, the ice lens thickness has a negligible effect on simulated $T_{\mathrm{B}}$. Hence, because no precise measurements of ice lens thickness were performed in the field, ice lens thickness was set to $1 \mathrm{~cm}$ in DMRT-ML. 
Table 5. Same as Table 1 but for Umiujaq sites (UMI).

\begin{tabular}{llllllllll}
\hline SP & Type & $\begin{array}{l}\text { SD } \\
(\mathrm{cm})\end{array}$ & $\begin{array}{l}T_{\text {snow }} \\
(\mathrm{K})\end{array}$ & $\begin{array}{l}\rho_{\text {snow }} \\
\left(\mathrm{kg} \mathrm{m}^{-3}\right)\end{array}$ & $\begin{array}{l}R_{\text {opt }} \\
(\mathrm{mm})\end{array}$ & $\begin{array}{l}T_{\text {soil }} \\
(\mathrm{K})\end{array}$ & IC & B Date \\
\hline UMI-1 & Tundra & 35 & $253.9(2.6)$ & $438.6(195.0)$ & $0.15(0.12)$ & 258.4 & 2 & $\mathrm{x}$ & 22 Jan 2014 \\
UMI-2 & & 70 & $256.2(4.6)$ & $420.7(146.6)$ & $0.18(0.09)$ & 265.2 & 2 & $\mathrm{x}$ & 23 Jan 2014 \\
\hline UMI-3 & Forest clearing & 132 & $263.5(5.8)$ & $319.0(51.2)$ & $0.18(0.08)$ & 271.8 & 0 & $\mathrm{x}$ & 24 Jan 2014 \\
\hline UMI-4 & Tundra & 57 & $256.9(4.2)$ & $311.7(142.4)$ & $0.23(0.11)$ & 264.4 & 1 & & 25 Jan 2014 \\
UMI-5 & & 93 & $254.0(3.9)$ & $350.6(42.3)$ & $0.19(0.09)$ & 261.6 & 0 & x & 26 Jan 2014 \\
\hline
\end{tabular}

\subsubsection{Bridging}

It has been shown that DMRT theory is in agreement with numerical solutions of the 3-D Maxwell equations up to a density of $275 \mathrm{~kg} \mathrm{~m}^{-3}$ (ice fraction of $0-0.3$ ) (Tsang et al., 2008), which is a relatively low density for snow. Although most of the applications of DMRT theory concern snow, DMRT can be applied to other dense media such as bubbly ice (Dupont et al., 2014). In this case, the background is pure ice, and the scatterers are air spheres to represent bubbles. To the best of our knowledge, no validity tests have been done in this configuration; but if we assume a similar range of validity in terms of volume fraction of scatterers, the DMRT theory would be valid in the range 0.7-1 for the ice fraction, that is $642-917 \mathrm{~kg} \mathrm{~m}^{-3}$. Even in this case, a large range of intermediate densities remains for which the absorption and scattering coefficients might not be accurate. Following Dierking et al. (2012), an empirical extrapolation of these coefficients from a spline fitted in both validity ranges was implemented to calculate coefficients for a layer with an ice fraction between $0.4\left(\rho_{\text {snow }}=367 \mathrm{~kg} \mathrm{~m}^{-3}\right)$ and 0.6 $\left(\rho_{\text {snow }}=550 \mathrm{~kg} \mathrm{~m}^{-3}\right)$ (Fig. 3). As an example, the bridging leads to a decrease of $T_{\mathrm{B}}$ at $37 \mathrm{GHz}$ for high snow density (> $350 \mathrm{~kg} \mathrm{~m}^{-3}$ ) related to the increase of scattering (Fig. 4). In the following, this approach is denoted as "bridging" and the limits will be set at 0.4 and 0.6 for the ice fraction following the study of Dierking et al. (2012).

The implementation of the snow pit bridging was evaluated with James Bay and Umiujaq snow pit data that include at least one snow layer with an ice fraction of more than 0.4 (Tables 2 and 5). Because $\rho_{\text {snow }}$ is relatively low in boreal regions due to weakening of the wind by trees, we also evaluated this approximation using a tundra data set to increase the number of high-density snow layers for the specific validation of the bridging. The database acquired at the Churchill Northern Studies Center (58 $44^{\prime}$ N, 93⒋ $9^{\prime}$ W) (Roy et al., 2013; Derksen et al., 2012) from the winter 2010 campaign is composed of 13 sites with at least one layer in the bridging range.

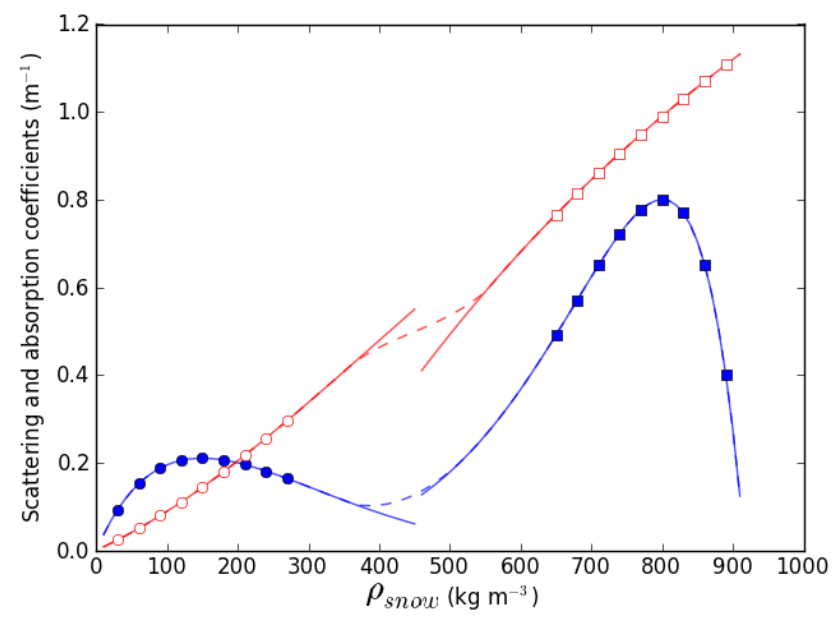

Figure 3. Absorption (red) and scattering (blue) coefficients as a function of $\rho_{\text {snow }}$ at $37 \mathrm{GHz}\left(T_{\text {snow }}=260 \mathrm{~K}, T_{\text {soil }}=270 \mathrm{~K}\right.$, $\mathrm{SD}=1.0 \mathrm{~m}$ and $R_{\text {eff }}=0.3 \mathrm{~mm}$ ). The dotted lines show the bridging implementation for an ice fraction between 0.4 and 0.6 .
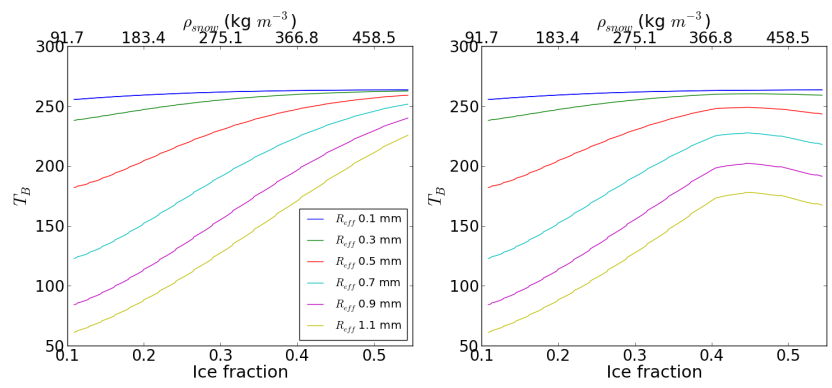

Figure 4. $T_{\mathrm{B}}$ without (left) and with the bridging implementation (right) at $37 \mathrm{GHz}(\mathrm{V}$-pol $)$ for different $R_{\text {eff }}\left(T_{\text {snow }}=260 \mathrm{~K}, T_{\text {soil }}=\right.$ $270 \mathrm{~K}$ and $\mathrm{SD}=1.0 \mathrm{~m})$.

\subsubsection{Soil model}

Soil reflectivity models are included in DMRT-ML to account for the soil contribution to the measured $T_{\mathrm{B}}$. In this paper, the Wegmüller and Mätzler (1999) soil reflectivity model improved for frozen soil by Montpetit et al. (2015) is used. The Wegmüller and Mätzler (1999) model for incidence an- 
Table 6. Main parameters used in DMRT-ML.

\begin{tabular}{lllllll}
\hline $\begin{array}{l}\text { Frequency } \\
(\mathrm{GHz})\end{array}$ & $\varepsilon^{\prime}$ & $\beta$ & $\phi$ & Fluxes & $\begin{array}{l}\sigma \\
(\mathrm{cm})\end{array}$ & $\begin{array}{l}\theta \\
\left({ }^{\circ}\right)\end{array}$ \\
\hline 11 & 3.197 & 1.077 & & & & \\
19 & 3.452 & 0.721 & 3.3 & 64 & 0.193 & 55 \\
37 & 4.531 & 0.452 & & & & \\
\hline
\end{tabular}

gles lower than $60^{\circ}$ is described by

$$
\begin{aligned}
& \Gamma_{f, \mathrm{H} \text {-pol }}=\Gamma_{f, \mathrm{H}}^{\mathrm{Fresnel}} \exp \left(-(k \sigma)^{\sqrt{-0.1 \cos \theta}}\right), \\
& \Gamma_{f, \mathrm{~V} \text {-pol }}=\Gamma_{f, \mathrm{H}} \cos \theta^{\beta},
\end{aligned}
$$

where $\Gamma_{f, p}$ is the rough soil reflectivity at a frequency $f$ and polarization $p(\mathrm{H}-$ pol or V-pol) by its smooth Fresnel reflectivity in $\mathrm{H}-\mathrm{Pol}\left(\Gamma_{f, \mathrm{H}}\right)$, which depends on the incidence angle $(\theta)$ and the real part of the soil permittivity $\left(\varepsilon^{\prime}\right)$, weighted by an attenuation factor that depends on the standard deviation in height of the surface (soil roughness, $\sigma$ ), the measured wave number $(k)$ and a polarization ratio dependency factor $(\beta)$. The values of $\varepsilon^{\prime}, \sigma$ and $\beta$ at 11,19 and $37 \mathrm{GHz}$ inverted by Montpetit et al. (2015) for frozen soil (Table 6) were used in this study. Montpetit et al. (2013) used independent snowfree ground-based radiometer angular measurements taken at James Bay site in 2013 (same campaign). The parameters were also validated over Umiujaq (same campaign) from snow removal experiment.

\section{Results}

In this section, the impact of model improvements (ice lenses and bridging) is first presented. Afterward, the evaluation of the effect of the different sources (soil, snow grain size, snow density, ice lenses and vegetation) on $T_{\mathrm{B}}$ is shown.

\subsection{Model validation and improvement}

Initial simulations ignoring the presence of ice lenses and bridging show a clear overestimation of $T_{\mathrm{B}}$ mostly at $\mathrm{H}$ pol. The observed root mean square error (RMSE) is greater than $35 \mathrm{~K}$ at 11 and $19 \mathrm{GHz}$ and greater than $20 \mathrm{~K}$ at $37 \mathrm{GHz}$ (Fig. 5). There is also a positive bias for $T_{\mathrm{B}}$ at 11 and $19 \mathrm{GHz}$ at V-pol. In this section, the effect of ice lenses on $T_{\mathrm{B}}$ is evaluated, while the bridging implementation was tested on snow pit data.

\subsubsection{Ice lenses}

Simulations including observed ice lenses were conducted on all snow pits (Fig. 6), leading to a strong decrease in simulated $T_{\mathrm{B}} \mathrm{H}$-pol (up to $40 \mathrm{~K}$ ). At H-pol, the RMSEs are thus improved by $15.4,23.4$ and $9.3 \mathrm{~K}$ at 11,19 (initially $>35 \mathrm{~K}$ ) and $37 \mathrm{GHz}$ (initially $>20 \mathrm{~K}$ ), respectively. The ice lenses

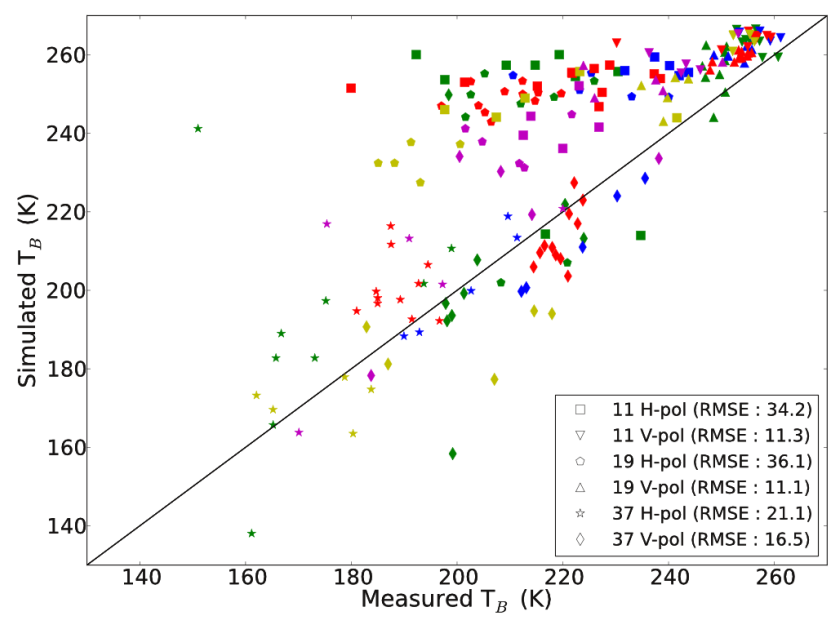

Figure 5. $T_{\mathrm{B}}$ simulated without ice lenses in DMRT-ML and bridging. RMSE (K) between measured and simulated $T_{\mathrm{B}}$ are given in parentheses. The symbol types correspond to the frequency and colors to the sites: red is $\mathrm{JB}_{\mathrm{Jan} \text {-transect }}$; green is $\mathrm{JB}_{\mathrm{Jan} \text {-others }}$; blue is $\mathrm{JB}_{\mathrm{Feb}}$; yellow is $\mathrm{JB}_{\mathrm{Mar}}$; magenta is UMI.

also slightly decrease the bias measured at V-pol for all frequencies leading to a RMSE improvement of 3-4 K. These results show that a simple ice lens implementation in DMRTML helps to simulate the strong reflection component of ice lenses (decrease of snowpack emissivity), leading to improved simulations of $T_{\mathrm{B}}$.

However, a large variability $(190-245 \mathrm{~K})$ in $T_{\mathrm{B}}$ observations at $\mathrm{H}$-pol at 11 and $19 \mathrm{GHz}$ is not reproduced by the simulations (dotted black line in Fig. 6). This feature suggests some limitations of ice lens and/or snow layering modeling in DMRT-ML that can be related to the fact that coherence effect is not taken into account. Note that this underestimation of $T_{\mathrm{B}}$ spatial variability is not related to the soil as it is demonstrated in Sect. 3.2.1. The modeling uncertainties related to ice lenses will be discussed more specifically in Sect. 3.2.4.

\subsubsection{Bridging}

To test the bridging parameterization (see Sect. 2.2.2), we used 13 tundra sites from the Churchill tundra database (Roy et al., 2013), 4 from Umiujaq and 2 from the James Bay snow pits. In each case, at least one snow layer with a snow density higher than $367 \mathrm{~kg} \mathrm{~m}^{-3}$ (ice fraction of 0.4: Dierking et al., 2012 ) is used. For each of the 19 sites studied, simulations at $37 \mathrm{GHz}$ (the most sensitive frequency to snow) with and without the bridging implementation were conducted (all input parameters kept the same). The bridging has a relatively modest impact on simulations with an improvement in the RMSEs of between 2 and $4 \mathrm{~K}$ at tundra sites (Umiujaq and James Bay). The greatest improvements are found for deep drifted tundra snow pits where there is a very thick wind slab 


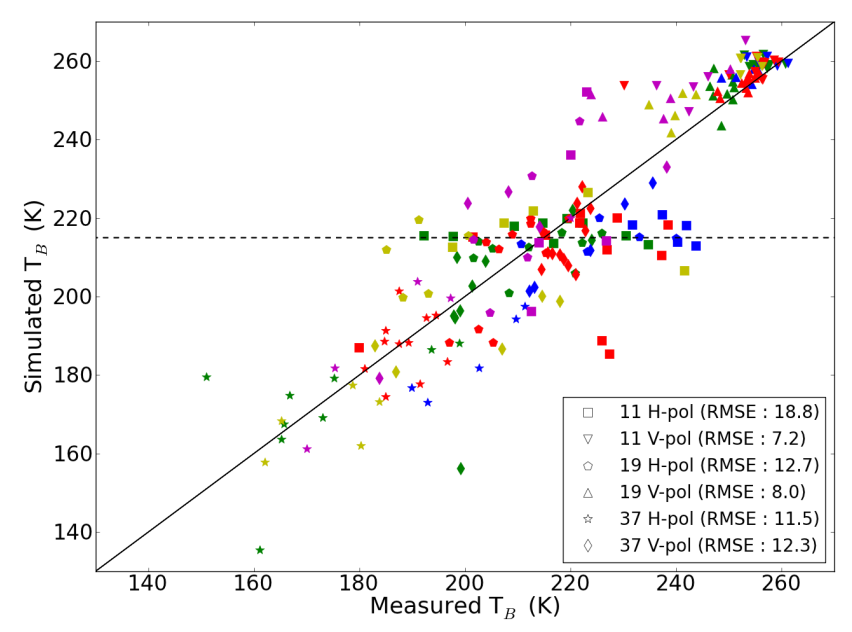

Figure 6. $T_{\mathrm{B}}$ simulated with ice lenses included in DMRT-ML but without bridging. The symbol types correspond to the frequency and colors to the sites: red is $\mathrm{JB}_{\mathrm{Jan} \text {-transect }}$; green is $\mathrm{JB}_{\mathrm{Jan} \text {-others }}$; blue is $\mathrm{JB}_{\mathrm{Feb}}$; yellow is $\mathrm{JB}_{\text {Mar }}$; magenta is UMI. The dotted black line represents the $T_{\mathrm{B}}$ where the simulations underestimated the spatial variability at 11 and $19 \mathrm{GHz} \mathrm{H}-$ pol.

with high $\rho_{\text {snow }}$ and small rounded grains are present at the top of the snowpack.

\subsection{Signal contributions and modeling uncertainties}

In the following, all DMRT-ML simulations consider the bridging implementation and include the observed ice lenses. Table 7 shows the overall RMSEs for all campaigns described in Sects. 3.3.1-3.3.4. The RMSE values oscillate between 7.8 and $21.5 \mathrm{~K}$ at H-pol (Table 7). Since V-pol is less affected by layering in the snowpack at 11 and $19 \mathrm{GHz}$, the RMSEs are generally lower (between 3.5 and $14.4 \mathrm{~K}$ ), while the RMSEs at $37 \mathrm{GHz}$ are similar at V-pol and H-pol. This is due to the higher sensitivity of higher frequencies to snow grain scattering when compared to the lower frequencies that are less affected by stratigraphy. Table 7 also suggests that the inclusion of bridging only decreases the RMSEs by $0.5 \mathrm{~K}$ and $0.3 \mathrm{~K}$ at $37 \mathrm{GHz}$ at $\mathrm{H}$-pol and V-pol, respectively. These RMSEs will thus be used as a reference to quantify the effect of spatial variability and uncertainty in measurements on the $T_{\mathrm{B}}$ simulations.

\subsubsection{Soil roughness}

The analysis of small-scale soil variability in modeling the $T_{\mathrm{B}}$ of snow-covered surfaces is conducted using the SEex from the transect during the $\mathrm{JB}_{\mathrm{Jan}}$ (mineral soil) and $\mathrm{JB}_{\mathrm{Feb}}$ campaigns (organic soil). The $\mathrm{JB}_{\mathrm{Jan}} \mathrm{SEex}$ data represent the variability within a $30 \mathrm{~m}$ transect in a relatively homogeneous mineral soil area (quarry). The $\mathrm{JB}_{\mathrm{Feb}}$ SEex were conducted at four different locations in clearings with organic soil and within about $1 \mathrm{~km}$ from each other. The strategy be-
Table 7. Overall RMSEs (K) between measured and simulated $T_{\mathrm{B}}$ for all sites considering ice lenses and bridging in DMRT-ML.

\begin{tabular}{llllll}
\hline & $\mathrm{JB}_{\mathrm{Jan}}$ & $\mathrm{JB}_{\mathrm{Feb}}$ & $\mathrm{JB}_{\text {Mar }}$ & $\mathrm{UMI}$ & All \\
\hline $11 \mathrm{H}$ & 21.5 & 13.6 & 18.2 & 14.3 & 18.8 \\
$11 \mathrm{~V}$ & 6.4 & 5.5 & 6.3 & 9.8 & 7.2 \\
$19 \mathrm{H}$ & 11.7 & 8.7 & 19.8 & 11.2 & 12.7 \\
$19 \mathrm{~V}$ & 3.5 & 5.7 & 9.2 & 13.4 & 8.0 \\
$37 \mathrm{H}$ & 12.1 & 15.1 & 9.7 & 9.7 & 11.5 \\
$37 \mathrm{~V}$ & 7.8 & 15.3 & 14.4 & 16.8 & 12.3 \\
\hline
\end{tabular}

hind the evaluation of the small-scale spatial variability on snow-covered $T_{\mathrm{B}}$ is to first calculate the soil emission variability (optimization of $\sigma$ ) from SEex measurements. This variability is then introduced in the simulations with snowcovered surfaces to evaluate the sensitivity of $T_{\mathrm{B}}$ to variability in the emission of frozen soil.

For each SEex measurement, the surface roughness parameter $\sigma$ was optimized using the three frequencies and both polarizations for bare soil measurements. The $\sigma$ value was changed by increments of $0.01 \mathrm{~cm}$, up to $1 \mathrm{~cm}$ (Eqs. 3 and 4) and the associated $\mathrm{RMSE}_{\sigma}$ was calculated as a function of the measured $T_{\mathrm{B}}\left(T_{\mathrm{B}, \mathrm{mes}}\right)$ and simulated $T_{\mathrm{B}}\left(T_{\mathrm{B}, \mathrm{sim}}\right)$ in $\mathrm{V}$-pol and H-pol as follows:

$\mathrm{RMSE}_{\sigma}=$

$$
\sqrt{\frac{\sum_{j=1}^{3} \sum_{i=1}^{N}\left(T_{\mathrm{B}, \mathrm{sim} ; i}^{j \mathrm{~V}}-T_{\mathrm{b}, \mathrm{mes} ; i}^{j \mathrm{~V}}\right)^{2}+\left(T_{\mathrm{B}, \mathrm{sim} ; i}^{j \mathrm{H}}-T_{\mathrm{B}, \mathrm{mes} ; i}^{j \mathrm{H}}\right)^{2}}{6 N}},
$$

where $j$ corresponds to the frequencies ( $j=1,2,3$, respectively, for 11,19 and $37 \mathrm{GHz}$ ) and $i$ corresponds to the sites. The optimal $\sigma$ was determined by the lowest $\operatorname{RMSE}_{\sigma}$ (Eq. 5) value for all sites at $\mathrm{JB}_{\mathrm{Jan}}$ and $\mathrm{JB}_{\mathrm{Feb}}$.

The optimization was also done for each site individually to estimate the spatial variability in $\sigma$. The results presented in Fig. 7 show that a clear minimum in the $\mathrm{RMSE}_{\sigma}$ can be found at every site. Figure 7 (right) shows that the optimal $\sigma$

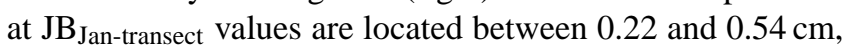
while 0.31 is found for all five sites. The variability can be explained by the variation of the gravel size that affects the surface roughness. For $\mathrm{JB}_{\mathrm{Feb}}$, the observed spatial variability is more significant with variations ranging between $0.195 \mathrm{~cm}$ and $1.987 \mathrm{~cm}$ with an optimized $\sigma=0.411 \mathrm{~cm}$ for all four sites (Fig. 7 left). However, one should be careful in interpreting these results as the optimization could also compensate for uncertainties in the permittivity of frozen ground. Nevertheless, because the minimal and maximal values of optimized $\sigma$ are taken, this does not affect our main goal, which is to estimate the variability in snow-covered $T_{\mathrm{B}}$ introduced by the soil in the model. Furthermore, as mentioned in Sect. 2.2.3, the permittivity used in this study were retrieved at the same site as this study. 

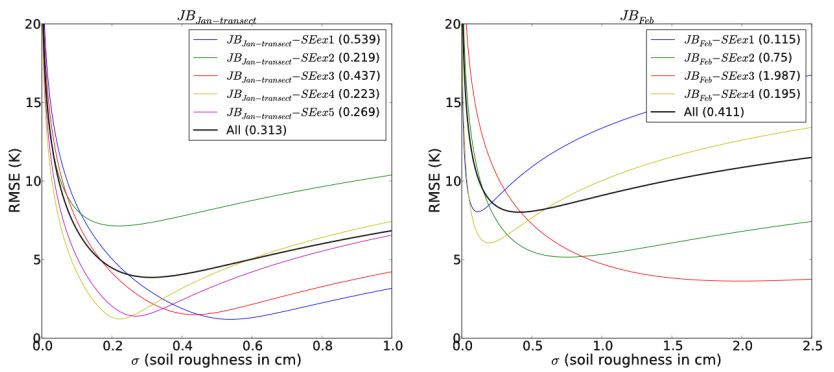

Figure 7. $\mathrm{RMSE}_{\sigma}$ for bare frozen soil sites (snow excavation experiment, SEex) as a function of soil roughness $(\sigma)$ for (left) $\mathrm{JB}_{\mathrm{Jan} \text {-transect }}$ and (right) $\mathrm{JB}_{\mathrm{Feb}}$. The optimized $\sigma$ for each site is given in parentheses.
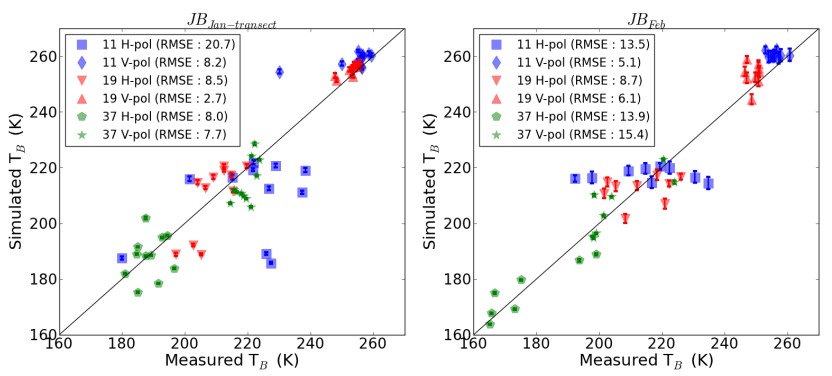

Figure 8. Sensitivity of snow-covered surface $T_{\mathrm{B}}$ to the variation

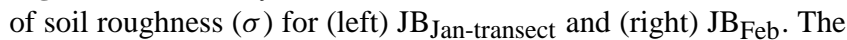
error bars show the variation of $T_{\mathrm{B}}$ for maximum and minimum optimized $\sigma$ derived from SEex during both campaigns (Fig. 7). The RMSE $(\mathrm{K})$ values correspond to the retrievals using the initial (Table 6) $\sigma$ value.

We evaluated the small-scale spatial variability of soil emissivity resulting from the observed roughness variability. For the sites with observations taken with snow on the ground (Tables 1-3 and 5, for both campaigns), we simulated the $T_{\mathrm{B}}$ with DMRT-ML considering the lowest and highest optimized $\sigma$ (see Fig. 7). Note that we have not used the standard deviation of $\sigma$ that would have led to negative values. Figure 8 (left) shows that the $T_{\mathrm{B}}$ sensitivity to the variation of soil roughness is very weak. $T_{\mathrm{B}}$ variations of 0.5 and $1.3 \mathrm{~K}$ were observed at the $\mathrm{JB}_{\mathrm{Jan}-\text { transect }}$ site where the soil properties were more homogeneous (mineral soil), while a variation of 0.7 to $3.8 \mathrm{~K}$ was measured at the $\mathrm{JB}_{\mathrm{Feb}}$ site with organic soil (Table 8). The sensitivity is higher at 11 and $19 \mathrm{GHz}$ because the soil emission is less attenuated by snow grain scattering. We also performed the same calculation without the ice lens implementation where results are similar (less than $1 \mathrm{~K}$ change), suggesting that, despite a potential low transmissivity, ice lenses are not responsible for the attenuation of the soil upwelling emission.

The results show that the soil small-scale spatial variability is much lower than the RMSEs for most of the frequencies and polarizations (Tables 7 and 8). However, for 11 and $19 \mathrm{GHz}$ at V-pol, the soil-induced variability calculated
Table 8. $T_{\mathrm{B}}$ sensitivity $\left(\Delta T_{\mathrm{B}}\right)(\mathrm{K})$ associated with the small-scale variability of soil roughness $(\sigma)$.

\begin{tabular}{lll}
\hline & BJ Jan-transect $_{\text {J }}$ & BJ $_{\text {Feb }}$ \\
\hline $11 \mathrm{H}$ & 1.3 & 3.8 \\
$11 \mathrm{~V}$ & 1.3 & 3.8 \\
$19 \mathrm{H}$ & 1.2 & 3.2 \\
$19 \mathrm{~V}$ & 1.4 & 3.5 \\
$37 \mathrm{H}$ & 0.5 & 0.7 \\
$37 \mathrm{~V}$ & 0.6 & 0.7 \\
\hline
\end{tabular}

during $\mathrm{JB}_{\mathrm{Feb}}$ campaign leads to $\Delta T_{\mathrm{B}}$ values (Table 8) similar to the measured RMSEs (Table 7). Hence, the modeling error cannot be solely explained by small-scale variability in the emissivity of frozen soil, except possibly for 11 and $19 \mathrm{GHz}$ at V-pol. However, these conclusions are only valid for frozen soils, but the higher dielectric contrast of thawed soil would have a greater impact on the emissivity of snowcovered surfaces.

\subsubsection{Snow grain size}

To test the sensitivity of the simulations to the grain size (SSA) measurement errors, the simulations considered an error of $12 \%$ in SSA when using the shortwave infrared reflection measurement approach as reported in Gallet et al. (2009). Hence two simulations were conducted: one with all SSA data along the profile increased by $12 \%$ $\left(T_{\mathrm{B}, \mathrm{SSA}}+12 \%\right)$, and one with all SSA data decreased by

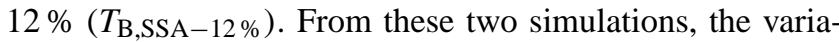
tion of $T_{\mathrm{B}}$ related to SSA errors $\left(\Delta T_{\mathrm{B}, \mathrm{SSA}}: T_{\mathrm{B}, \mathrm{SSA}+12 \%-}\right.$ $T_{\mathrm{B}, \mathrm{SSA}}-12 \%$ ) was calculated, keeping in mind that this should be the maximum $\Delta T_{\mathrm{B}}$ error, since the variations in SSA are all in the same direction for the whole profile. The soil parameterization is kept the same for all sites (see Table 6).

Figure 9 shows the error bars related to a variation of $+12 \%$ in SSA (upper bars: higher SSA leads to smaller grains and less scattering) and $-12 \%$ (lower bars: lower SSA leads to larger grains and more scattering). The results show that $37 \mathrm{GHz}$ is the most sensitive to the grain size with variations between 16.2 and $27.4 \mathrm{~K}$ (Table 9). The variations are generally higher at V-pol, which has a higher penetration depth with less sensitivity to stratification and ice lenses. As such, $37 \mathrm{GHz}$ is more influenced by large depth hoar grains at the bottom of the snowpack. Hence, because the relationship between the scattering and the particle size reaches a maximum sensitivity within the particle range (Picard et al., 2013), the variation of $12 \%$ for depth hoar SSA will cause a higher increase of $\Delta T_{\mathrm{B}, \mathrm{SSA}}$. In all cases, $\Delta T_{\mathrm{B}, \mathrm{SSA}}$ are higher than the RMSEs (Table 7), suggesting that grain size can explain the uncertainty in the $T_{\mathrm{B}}$ simulations.

At $19 \mathrm{GHz}$, there is an increase in $\Delta T_{\mathrm{B}, \mathrm{SSA}}$ of about $7 \mathrm{~K}$ at V-pol and H-pol during the three James Bay campaigns. This increase of $\Delta T_{\mathrm{B}, \mathrm{SSA}}$ is linked to snow grain metamor- 

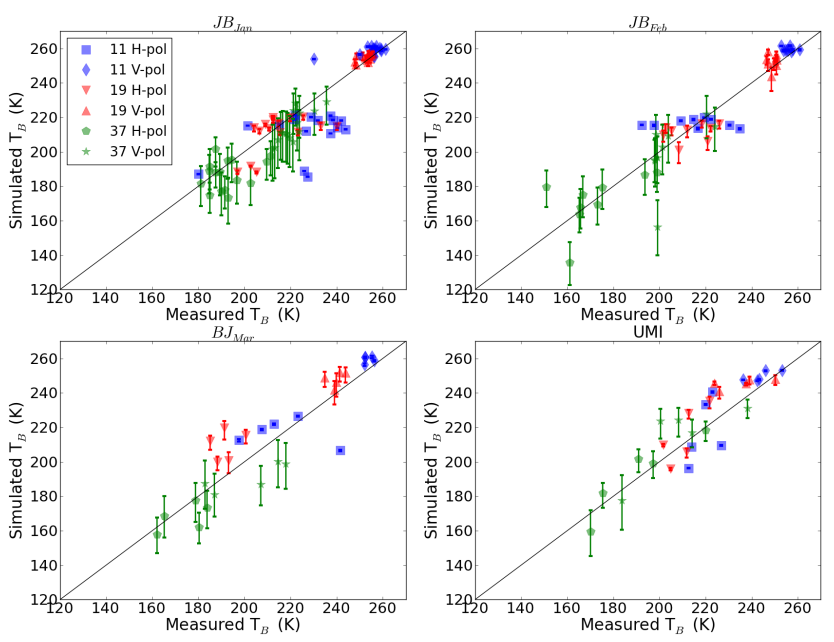

Figure 9. $T_{\mathrm{B}}$ sensitivity associated to the error of SSA measurements $(12 \%)$ for the James Bay (three dates) and Umiujaq sites.

Table 9. $T_{\mathrm{B}}$ sensitivity $\left(\Delta T_{\mathrm{B}, \mathrm{SSA}}: T_{\mathrm{B}, \mathrm{SSA}+12 \%}-T_{\mathrm{B}, \mathrm{SSA}-12 \%}\right)$ $(\mathrm{K})$ associated with the error of SSA measurements

\begin{tabular}{lllll}
\hline & $\mathrm{BJ}_{\mathrm{Jan}}$ & $\mathrm{BJ}_{\mathrm{Feb}}$ & $\mathrm{BJ}_{\text {Mar }}$ & $\mathrm{UMI}$ \\
\hline $11 \mathrm{H}$ & 0.3 & 0.7 & 1 & 0.5 \\
$11 \mathrm{~V}$ & 0.3 & 0.7 & 1.1 & 0.5 \\
$19 \mathrm{H}$ & 2.8 & 6.5 & 10 & 4.5 \\
$19 \mathrm{~V}$ & 3.3 & 6.9 & 11.1 & 4.5 \\
$37 \mathrm{H}$ & 21.2 & 21.6 & 22.5 & 16.2 \\
$37 \mathrm{~V}$ & 27.4 & 26.7 & 25.9 & 18.6 \\
\hline
\end{tabular}

phism (Colbeck, 1983) that tends to increase the particle size through the winter (see Tables 1-3). With a higher sensitivity on the particle range and the dependence of scattering to the particle size, the variation of large grains will increase $\Delta T_{\mathrm{B}, \mathrm{SSA}}$. This phenomenon shows that at $19 \mathrm{GHz}$, the effect of SSA measurement uncertainty on $T_{\mathrm{B}}$ depends on the type of grains. For small snow grains in January, the error in SSA is small compared to the RMSE, which is not the case in March when the error is closest to the RMSE in the presence of larger grains. A very small increase of $\Delta T_{\mathrm{B}, \mathrm{SSA}}$ is also seen at $11 \mathrm{GHz}$ but with much lower $\Delta T_{\mathrm{B}, \mathrm{SSA}}$ (less than $1 \mathrm{~K}$ ). These results show that scattering is negligible at $11 \mathrm{GHz}$ for seasonal snow, even with large grains such as depth hoar.

We assessed average variation in $T_{\mathrm{B}}$ resulting from 100 runs with random error between $\pm 12 \%$ applied to SSA for each layer and snow pit. As expected, the results show that the variations between initial simulation and simulation with random error on SSA are significantly lower than those shown in Table 9. With random error applied on SSA measurements, the variations are lower than $1 \mathrm{~K}$ at 11 and $19 \mathrm{GHz}$ and between 2 and $3 \mathrm{~K}$ at $37 \mathrm{GHz}$. These values give the lower limits of $T_{\mathrm{B}}$ error related to SSA uncertainties, while values in Table 9 give the highest limit of the variation in $T_{\mathrm{B}}$.
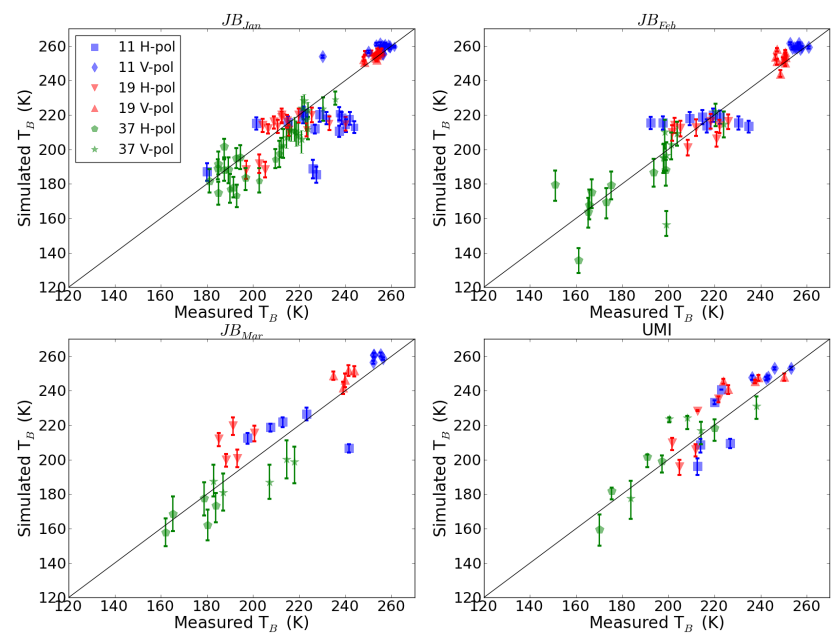

Figure 10. $T_{\mathrm{B}}$ sensitivity associated with the error in snow density measurements $( \pm 10 \%)$. The ice lens density remains at $900 \mathrm{~kg} \mathrm{~m}^{-3}$.

Table 10. $\quad T_{\mathrm{B}} \quad$ sensitivity $\left(\Delta T_{\mathrm{B}} \rho_{\text {snow }}: T_{\mathrm{B}} \rho_{\text {snow }+10 \%}-\right.$ $T_{\mathrm{B}} \rho_{\text {snow }-10 \%}$ ) (K) associated with the error in snow density measurements.

\begin{tabular}{lllll}
\hline & BJ Jan $_{\text {J }}$ & BJ $_{\mathrm{Feb}}$ & $\mathrm{BJ}_{\mathrm{Mar}}$ & $\mathrm{UMI}$ \\
\hline $11 \mathrm{H}$ & 7.6 & 7.5 & 5.6 & 6.1 \\
$11 \mathrm{~V}$ & 1.4 & 1.4 & 2.1 & 1.9 \\
$19 \mathrm{H}$ & 8 & 8.8 & 8.3 & 6.2 \\
$19 \mathrm{~V}$ & 2.4 & 3.2 & 6.7 & 3.6 \\
$37 \mathrm{H}$ & 13.5 & 16.5 & 18.4 & 11.6 \\
$37 \mathrm{~V}$ & 12.6 & 15.3 & 21.4 & 13.4 \\
\hline
\end{tabular}

\subsubsection{Snow density}

A similar analysis was conducted to evaluate the $T_{\mathrm{B}}$ sensitivity to an error in $\rho_{\text {snow }}$ of $\pm 10 \%\left(T_{\mathrm{B}} \rho_{\text {snow }}+10 \%\right.$ and $\left.T_{\mathrm{B}} \rho_{\text {snow }-10 \%}\right)$. The ice lens density was left at $900 \mathrm{~kg} \mathrm{~m}^{-3}$ and the variations in $T_{\mathrm{B}}$ related to the $\rho_{\text {snow }} \operatorname{error}\left(\Delta T_{\mathrm{B}} \rho_{\text {snow }}\right.$ : $T_{\mathrm{B}} \rho_{\text {snow }+10 \%}-T_{\mathrm{B}} \rho_{\text {snow }-10 \%}$ ) were calculated.

The highest sensitivity to $\rho_{\text {snow }}$ is seen at $37 \mathrm{GHz}$ (Fig. 10). The $\Delta T_{\mathrm{B}} \rho_{\text {snow }}$ are about $13 \mathrm{~K}$ during the $\mathrm{JB}_{\mathrm{Jan}}$ campaign and increase to $20 \mathrm{~K}$ for $\mathrm{JB}_{\mathrm{Mar}}$ (Table 10). Again, this increase is explained by the growth in snow grain size due to snow metamorphism that leads to lower density values. In the given range of sphere sizes and $\rho_{\text {snow }}$ at $37 \mathrm{GHz}$, the impact of $\rho_{\text {snow }}$ on $T_{\mathrm{B}}$ increases with a larger grain size (Fig. 3). These results show that the effect of $\rho_{\text {snow }}$ at $37 \mathrm{GHz}$ on DMRTML simulations depends on grain size and evolves throughout the winter due to snow metamorphism. It should, however, be noted that if the ice fraction limits of the bridging (Sect. 3.1.2) were extended to a lower ice fraction density, the impact for high $\rho_{\text {snow }}$ would be lower or even the opposite because of the increase in scattering due to bridging. Table 10 shows that $\Delta T_{\mathrm{B}} \rho_{\text {snow }}$ are of the same magnitude as 
RMSE. Hence, depending on the grain size, $\rho_{\text {snow }}$ can explain part of the error in the simulations.

At 11 and $19 \mathrm{GHz}$, the highest $\Delta T_{\mathrm{B}} \rho_{\text {snow }}$ are found at $\mathrm{H}$ pol with values around $7 \mathrm{~K}$ (Table 10). These highest values are related to the change in the permittivity discontinuity between layers, mostly at interfaces around the ice lenses, leading to a change in the reflectivity at the different interfaces (Montpetit et al., 2013). Because V-pol is less affected by horizontal layering, the effect is smaller. Hence, the effect of $\rho_{\text {snow }}$ uncertainty on $T_{\mathrm{B}}$ is lower than the measured RMSEs at 11 and $19 \mathrm{GHz}$ but has a significant impact on $T_{\mathrm{B}}$ at $\mathrm{H}-$ pol. These results are in agreement with studies that show that the microwave polarization ratio (H-pol / V-pol) can potentially be used for snow density retrievals (Champollion et al., 2013; Lemmetyinen et al., 2016).

\subsubsection{Ice lenses}

While including ice lenses in DMRT-ML significantly reduces the RMSE (Sect. 3.1.1), the underestimation of $T_{\mathrm{B}}$ variability remains strong at 11 and $19 \mathrm{GHz}$. Given that the remaining bias cannot be explained by the soil, grain size or $\rho_{\text {snow }}$ (Sects. 3.3.1, 3.3.2 and 3.3.3), we further explore here the role of ice lenses. The ice lens density $\left(\rho_{\mathrm{IL}}\right)$ variations can explain part of the variability as the density of ice influences the internal reflection (Durand et al., 2008; Rutter et al., 2013). In fact, ice lenses can be snow crusts with a density as low as $630 \mathrm{~kg} \mathrm{~m}^{-3}$ (Marsh and Woo, 1984). However, measuring the density of such layers is challenging and it was not attempted during our campaigns. The sensitivity was evaluated for a range of ice density between $700 \mathrm{~kg} \mathrm{~m}^{-3}$ $\left(T_{\mathrm{B}} \rho_{\mathrm{IL} 700}\right)$ and $917 \mathrm{~kg} \mathrm{~m}^{-3}\left(T_{\mathrm{B}} \rho_{\mathrm{IL} 917}\right)$ for all snow pits with ice lenses. The variation of $T_{\mathrm{B}}$ related to $\rho_{\mathrm{IL}}$ uncertainties $\left(\Delta T_{\mathrm{B}} \rho_{\mathrm{IL}}: T_{\mathrm{B}} \rho_{\mathrm{IL} 917}-T_{\mathrm{B}} \rho_{\mathrm{IL}} 700\right)$ was then calculated (all other parameters being constant).

Figure 11 shows that $\rho_{\mathrm{IL}}$ variations have a significant impact on $\mathrm{H}-$ pol $T_{\mathrm{B}}$ mostly at 11 and $19 \mathrm{GHz}$. The low $\Delta T_{\mathrm{B}} \rho_{\mathrm{IL}}$ at $37 \mathrm{GHz}$ (Table 11) is not related to the insensitivity of $37 \mathrm{GHz}$ to ice lenses but rather to the attenuation owing to snow grains dominating the effect of ice lenses. In fact, Table 11 shows that the effect of the variation of ice lens density decreases throughout the winter at James Bay because of increasing attenuation related to grain size metamorphism. It should be noted that no scattering occurs in these layers in the model because the $R_{\text {eff }}$ was kept null. Hence, $\rho_{\mathrm{IL}}$ can explain only the underestimation of $T_{\mathrm{B}}$, not the overestimation. Part of the error could be explained by the coherence that is not taken into account in DMRT-ML. The coherence is caused by multiple reflections within a thin layer and associated interference when the thickness of the ice lenses is less than a quarter of the wavelength $(\lambda / 4)$ (Mätzler et al., 1987; Montpetit et al., 2013). Since DMRT-ML does not take into account the coherence, the thickness of the ice layer has a negligible impact on $T_{\mathrm{B}}$ and was kept at $1 \mathrm{~cm}$. However, simulations with MEMLS accounting for coherence have shown
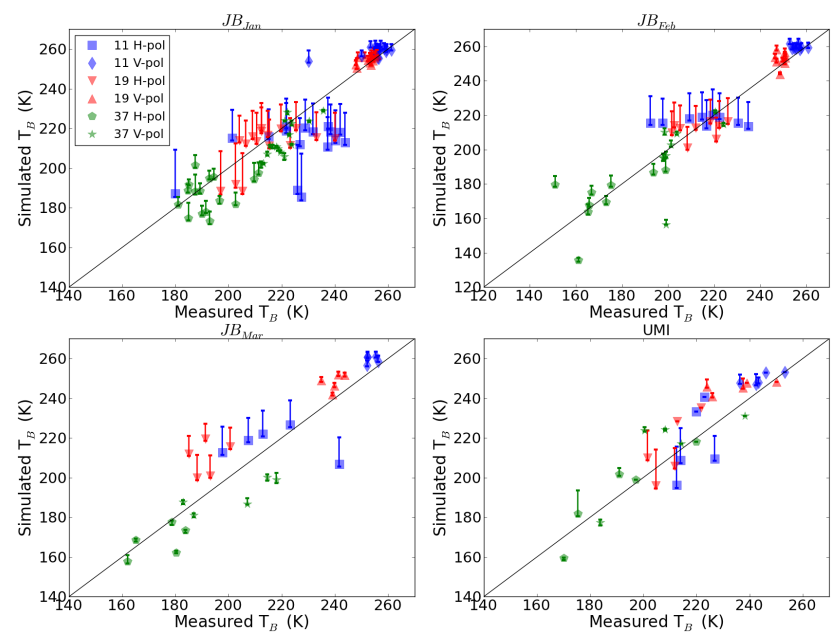

Figure 11. $T_{\mathrm{B}}$ sensitivity associated with the $\rho_{\mathrm{IL}}$ variation (700$917 \mathrm{~kg} \mathrm{~m}^{-3}$ ).

Table 11. $T_{\mathrm{B}}$ sensitivity $\left(\Delta T_{\mathrm{B}} \rho_{\mathrm{IL}}: T_{\mathrm{B}} \rho_{\mathrm{IL} 917}-T_{\mathrm{B}} \rho_{\mathrm{IL} 700}\right)(\mathrm{K})$ associated with the $\rho_{\mathrm{IL}}$ variation $\left(700-917 \mathrm{~kg} \mathrm{~m}^{-3}\right)$.

\begin{tabular}{lllll}
\hline & BJ $_{\text {Jan }}$ & BJ $_{\mathrm{Feb}}$ & $\mathrm{BJ}_{\mathrm{Mar}}$ & $\mathrm{UMI}$ \\
\hline $11 \mathrm{H}$ & 17 & 15.9 & 11.9 & 13.4 \\
$11 \mathrm{~V}$ & 3.7 & 3.1 & 2.6 & 3.5 \\
$19 \mathrm{H}$ & 15.4 & 14.3 & 9.2 & 12.1 \\
$19 \mathrm{~V}$ & 3.2 & 2.4 & 1.8 & 3.1 \\
$37 \mathrm{H}$ & 6.4 & 5.7 & 1.2 & 6.1 \\
$37 \mathrm{~V}$ & 0.8 & 1.5 & 1.7 & 1.1 \\
\hline
\end{tabular}

that variation in the ice lens thickness can change $T_{\mathrm{B}}$ by up to $100 \mathrm{~K}$ at $\mathrm{H}$-pol at 19 and $37 \mathrm{GHz}$ (Montpetit et al., 2013). Also, in this study, only the main ice lenses were noted and inserted in DMRT-ML. Many other melt/refreeze thin snow crusts were present but not recorded, and they can have a large impact on $T_{\mathrm{B}}$ observations (see Rutter et al., 2013). These thin crusts (less than $2 \mathrm{~mm}$ ) with a high density (over $600 \mathrm{~kg} \mathrm{~m}^{-3}$ ) can also have significant coherence effects (less than $\lambda / 4)$.

During the $\mathrm{JB}_{\mathrm{Jan}}$ campaign, at the transect, two ice lenses were observed at three consecutive snow pits $\left(\mathrm{JB}_{\mathrm{Jan}}-6.7\right.$, $\mathrm{JB}_{\mathrm{Jan}}-6.8$ and $\left.\mathrm{JB}_{\mathrm{Jan}}-6.9\right)$. The simulations at these sites show the three lowest simulated $T_{\mathrm{B}}$ at 11 and $19 \mathrm{GHz}$ at H-pol (Fig. 11). The second observed ice lens inserted in DMRT-ML significantly decreases the simulated $T_{\mathrm{B}}$. Including the second observed ice lens allows an improvement in the $T_{\mathrm{B}}$ simulation at $\mathrm{JB}_{\mathrm{Jan}}-6.8$ (Table 1 ), while the accuracy decreases for the two other snow pits, especially at $11 \mathrm{GHz}$. These results show the importance of small-scale spatial variability in the distribution of ice lenses. In this case, since the SBR footprint is not exactly where the snow pit was dug, the $11 \mathrm{GHz}$ measured the two ice lenses at $\mathrm{JB}_{\mathrm{Jan}}-6.8$, but not at $\mathrm{JB}_{\mathrm{Jan}}-6.7$ and $\mathrm{JB}_{\mathrm{Jan}}-6.9$. Rutter et al. (2013) showed that 


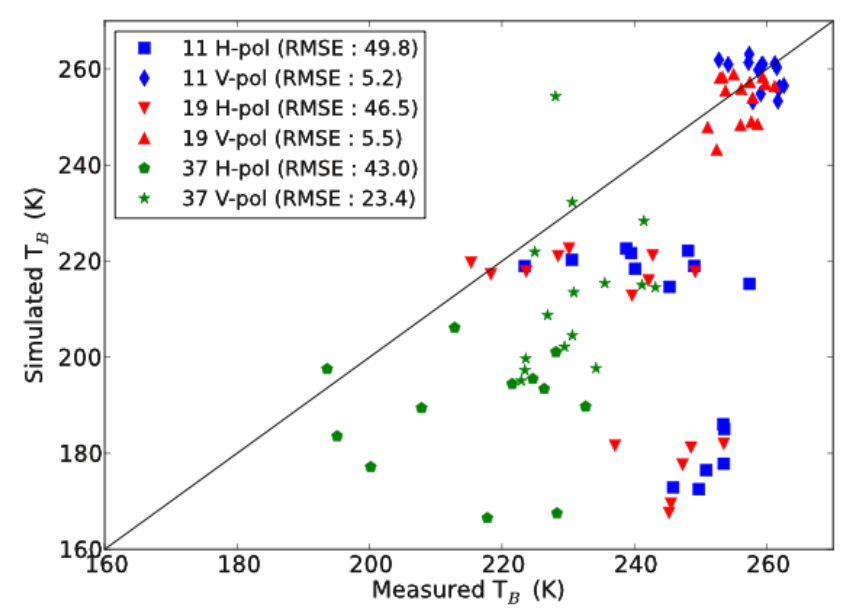

Figure 12. Simulated $T_{\mathrm{B}}$ in forested sites neglecting the vegetation contribution $\left(T_{\mathrm{B}, \text { down }}\right)$.

Table 12. Comparison between the calculated biases in an open area and in a forested area.

\begin{tabular}{lrr}
\hline & Bias $_{\text {open }}$ & Bias $_{\text {forest }}$ \\
\hline $11 \mathrm{H}$ & 4.7 & -41.7 \\
$11 \mathrm{~V}$ & -4.0 & -1.1 \\
$19 \mathrm{H}$ & -4.0 & -35.9 \\
$19 \mathrm{~V}$ & -5.7 & -3.4 \\
$37 \mathrm{H}$ & 2.2 & -37.4 \\
$37 \mathrm{~V}$ & 3.3 & -21.4 \\
\hline
\end{tabular}

such small-scale discontinuities in ice lenses have a strong impact on $T_{\mathrm{B}}$.

\subsubsection{Surrounding vegetation effects}

In a forested area, tree emission reflected by the snowpack can significantly contribute to the measured $T_{\mathrm{B}}$ on the ground (Roy et al., 2012). An analysis was conducted on 18 site measurements taken in a forest during the three James Bay campaigns (Table 4) to quantify the forest contributions to measured $T_{\mathrm{B}}$ using DMRT-ML. A first simulation, neglecting the emission coming from the trees in the downwelling $T_{\mathrm{B}}$ ( $T_{\mathrm{B}, \text { down }}$ ) reflected by the surface was conducted. Figure 12 shows a clear underestimation (biases $\approx 40 \mathrm{~K}$ at $\mathrm{H}$-pol) of simulated $T_{\mathrm{B}}$ at all frequencies, except for 11 and $19 \mathrm{GHz}$ at V-pol. Table 12 shows that these biases are much greater than the uncertainties induced by the snow cover in open areas, showing that the tree emission reflected by the surface significantly increased the measured $T_{\mathrm{B}}$. The low influence of vegetation (low bias forest: Table 12) at 11 and $19 \mathrm{GHz}$ Vpol is explained by the fact that the reflectivity of the surface at these frequencies is very low because the volume scattering is weak and the reflectivity at the interfaces is close to 0 near the Brewster angle.
Table 13. Average optimized $T_{\mathrm{B} \text {,down }}$ and standard deviation (in parentheses) (K).

\begin{tabular}{llll}
\hline & $11 \mathrm{GHz}$ & $19 \mathrm{GHz}$ & $37 \mathrm{GHz}$ \\
\hline$T_{\mathrm{B}, \text { down }}(\mathrm{K})$ & $147( \pm 64)$ & $120( \pm 74)$ & $110( \pm 43)$, \\
\hline
\end{tabular}

To quantify the forest contribution, the $T_{\mathrm{B} \text {,down }}$ was inverted with DMRT-ML. From the simulated $T_{\mathrm{B}}$ neglecting the forest contribution (Fig. 12), an iteration process was performed to find the $T_{\mathrm{B} \text {,down }}$ value that minimized the $\mathrm{RMSE}_{\mathrm{veg}}$ between simulated and measured $T_{\mathrm{B}}$ at V-pol and H-pol for each frequency independently:

$\mathrm{RMSE}_{\mathrm{veg}}=$

$\sqrt{\frac{\sum_{i=1}^{N}\left(T_{\mathrm{B}, \mathrm{sim} ; i}^{f \mathrm{~V}}-T_{\mathrm{B}, \mathrm{mes} ; i}^{f \mathrm{~V}}\right)^{2}+\left(T_{\mathrm{B}, \mathrm{sim} ; i}^{f \mathrm{H}}-T_{\mathrm{B}, \text { mes } ; i}^{f \mathrm{H}}\right)^{2}}{2 N}}$

where $f$ is the frequency.

Table 13 shows that the averaged optimized $T_{\mathrm{B} \text {,down }}$ are 147,120 and $110 \mathrm{~K}$, respectively, at 11,19 and $37 \mathrm{GHz}$. The optimized $T_{\mathrm{B} \text {,down }}$, however, decrease with frequency, which is opposite to what was shown in other studies (Kruopis et al., 1999; Roy et al., 2012, 2014). This is probably related to the inherent error in the snow surface $T_{\mathrm{B}}$ simulation in DMRTML (Table 7), which induces error in the calculation of the reflectivity of the snow-covered surface.

Table 13 also shows that there are large variations between the different snow pits with a standard deviation between 43 and $74 \mathrm{~K}$. The average $T_{\mathrm{B} \text {,down }}$ of the three frequencies was calculated for each site and compared with $\chi_{\text {veg }}$ obtained from fisheye pictures taken at the $12 \mathrm{JB}_{\mathrm{veg}}$ sites in January and February (fisheye pictures were not taken in March). Figure 13 shows that there is a good correlation $\left(\mathrm{R}^{2}=0.75\right)$ between averaged $T_{\mathrm{B} \text {,down }}$ (mean for the three frequencies) and $\chi_{\text {veg. }}$. These results confirm that the optimized $T_{\mathrm{B} \text {,down }}$ are related to the tree emission reflected by the surface (see an example of variations in Fig. 2). For comparison, the calculated atmospheric downwelling contributions were around $6 \mathrm{~K}$ at $11 \mathrm{GHz}$ and $25 \mathrm{~K}$ at $37 \mathrm{GHz}$. It also shows the potential of using fisheye pictures to quantify tree microwave emission in boreal forests. However, further considerations are necessary to improve the method. Because of the non-Lambertian component of the snow reflection and the non-homogeneity of the trees surrounding the site measurements, the direction (azimuth) in which the SBR is pointing has an important influence on the signal (Courtemanche et al., 2015). DMRTML assumed that the $T_{\mathrm{B} \text {,down }}$ is isotropic and does not take into account these specular components. For example, the $T_{\mathrm{B}}$ will be higher if the SBR is pointing in the direction of a large trunk close to the snow pit instead of pointing in the direction of a forest opening. 


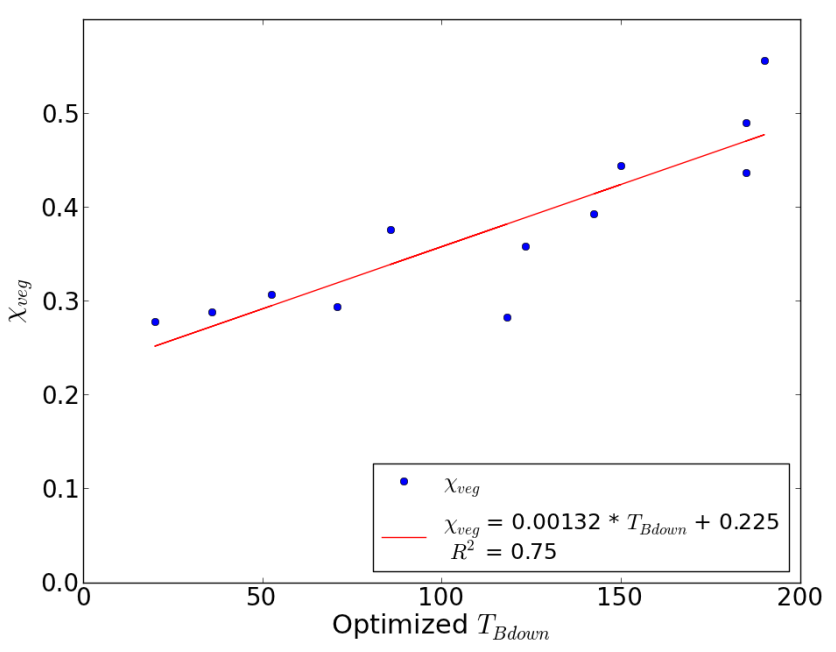

Figure 13. Relationship between the average $T_{\mathrm{B} \text {,down }}$ of the three frequencies and the proportion of pixels occupied by vegetation (trees) in the fisheye pictures $\left(\chi_{\mathrm{veg}}\right)$ for the $12 \mathrm{JB}_{\mathrm{veg}}$ sites in January and February.

\section{Discussion/conclusion}

This study presents a comprehensive analysis of the geophysical factors contributing to uncertainty in DMRT-ML for snow-covered surfaces in boreal forest, subarctic and arctic environments. A unique in situ database, including key information on the snowpack temporal winter evolution, allowed the assessment of the impact of spatial variability of (1) soil emission, (2) errors in snow grains and (3) density measurements, (4) ice lenses and (5) vegetation emission reflected from the surface on DMRT-ML simulations.

The implementation in DMRT-ML of the bridging aiming at filling the gap between low and high snow density ranges where the theory is invalid has been tested. Bridging leads to a small improvement for tundra snow where wind slabs are present. These improvements are modest and could compensate for the measurement uncertainties or other limitations related to the use of the model such as stickiness and grain size distribution (Roy et al., 2013). Based on the work of Dierking et al. (2012), the range of the ice fraction where bridging was applied was limited to $0.4-0.6$ but could be extended and lead to a stronger impact of bridging on the results (Tsang et al., 2008). However, as shown in this study, the uncertainties in measurements make it difficult to make sure that any optimization of the bridging range does not compensate for other uncertainties. In practice, this new version of DMRTML with bridging facilitates simulation of snow and/or ice without identification of the snow layer state.

Based on several snow removal experiments, the study shows that small-scale variability in soil emissivity in a boreal forest has a second-order effect on the snow-covered surface $T_{\mathrm{B}}$ when the soil is frozen, even for lower frequencies that are more transparent to the snowpack (11 and $19 \mathrm{GHz})$.
In practice, this implies that the use of constant soil parameters for frozen soil emission modeling for a given environment is adequate for snow emission studies. This result is surprising since soil roughness, soil wetness, freeze/thaw state and stratigraphy are usually difficult to measure in boreal conditions. However, further experiments should be done to validate this aspect for other types of environments. Exploring larger scales could help to determine at what scale soil emissivity has an influence on snow-covered $T_{\mathrm{B}}$.

This study shows the strong sensitivity of DMRT-ML to snow grain size and density at $37 \mathrm{GHz}$ and that the error related to the measurements can explain most of the RMSEs at this frequency and probably at higher frequencies. These results are in agreement with studies using MEMLS (Durand et al., 2008) and HUT (Rutter et al., 2013; Lemmetyinen et al., 2015). It remains difficult to distinguish the sources of error related to DMRT-ML simulations at $37 \mathrm{GHz}$. The study, however, underlines that measurement error limits the accuracy of the simulations. The error related to the physical simplifications in DMRT-ML was not investigated in this work, but our results suggest that the level of confidence of measurements is too low to test or significantly improve the DMRTML physics. In this study, SSA was used because it is a robust and objective metric that can be measured effectively on the field. However, the derived $R_{\text {opt }}$ metric used in DMRTML is related to an optical definition (Grenfell and Warren, 1999) and might not represent the grain for microwave wavelength (Mätzler, 2002). Further experiments on isolated snow layers as done by Wiesmann et al. (1998), but using new tools for snow microstructure parameterization could be applied to improve the physics of emission models. For example, more precise measurements of snow microstructure like X-ray tomography (Heggli et al., 2011) and the snow micro-penetrometer (SMP) (Schneebeli et al., 1999; Proksch et al., 2015) could be the next step to improve the understanding of the physics in DMRT-ML (e.g., Löwe and Picard, 2015). However, each snow microstructure measurement method has its own limitations. Combining the different information could be an avenue to better quantify the snow scattering mechanism in DMRT-ML.

This analysis confirms that the scaling factor $(\varphi=3.3)$ proposed by Roy et al. (2013) is a general value as it yields accurate results with the new data set presented in this paper. We do not pretend that this value exactly applies to other environments as Picard et al. (2014) found a lower value (2.3) for Antarctica with a SSA measurement technique that was intercalibrated with ours. The temporal analysis during the three campaigns in James Bay, however, shows that the sensitivity to snow measurement uncertainties evolve during winter due to snow metamorphism. This sensitivity change is also important at $19 \mathrm{GHz}$. Although snow is almost transparent at this frequency at the beginning of winter when the grains are small, $T_{\mathrm{B}}$ at $19 \mathrm{GHz}$ becomes sensitive to snow in March because of snow grain growth. This could be of interest for the SWE retrieval approach, knowing that $19 \mathrm{GHz} T_{\mathrm{B}}$ 
becomes sensitive to snow when snow grains become larger. As proposed in Derksen (2008) 11 and $19 \mathrm{GHz}$ frequencies could be useful for SWE retrievals for deep snow to overcome the problem of saturation at $37 \mathrm{GHz}$ (see Rosenfeld and Grody, 2000). At $11 \mathrm{GHz}$, snow is almost transparent throughout the winter demonstrating the utility of this band for monitoring soil conditions (phase, temperature) under the snow (Kohn and Royer, 2010).

The inclusion of ice lenses in DMRT-ML significantly improves the simulations at H-pol. However, the model is not able to reproduce the observed spatial variability at 11 and $19 \mathrm{GHz}$ at $\mathrm{H}$-pol, which was shown to be related to snowpack stratigraphy inaccuracies, mostly related to ice lenses and strong variations in snow density (for example, thin snow crust). The large spatial variability of ice lenses and snow crusts at the meter scale (Rutter et al., 2013) can lead to the strong spatial variability of observed $T_{\mathrm{B}}$. This ice lenses and snow crust spatial variability raise the need to develop efficient and practical methods to effectively characterize ice lenses and thin snow crusts, especially their density (Marsh and Woo, 1984). Using shortwave infrared photography (Montpetit et al., 2012) or SMP profiles (Proksch et al., 2015) are possible options. The coherence, which is not taken into account in DMRT-ML, is responsible for a large sensitivity of $T_{\mathrm{B}}$ to ice lens thickness and can explain the observed $T_{\mathrm{B}}$ variability at 19 and $11 \mathrm{GHz}$ at $\mathrm{H}$-pol. The implementation of the coherence in DMRT-ML is not difficult, but collecting the input variables in the field remains the major challenge.

In boreal forest areas, our analysis shows that the vegetation emission reflected by the snow-covered surface can contribute more than $200 \mathrm{~K}$ and that neglecting the reflection of the signal on the snow surface can lead to a bias of up to $40 \mathrm{~K}$, mostly at H-pol where the surface reflectivity is the highest. This bias is coupled to the snow state, depending on the snow reflectivity. These results clearly show the importance of the vegetation contribution and avoiding this contribution in measurements imply to operate in clearings with minimal forest cover mostly on the opposite side of the measurements (specular contributions). However, some promising results on the use of fisheye photographs to quantify that vegetation contribution were shown. The use of a Lambertian microwave surface for retrieving the downwelling contribution in ground-based radiometric measurements (Courtemanche et al., 2015) may also be a promising avenue.

To the best of our knowledge, this is the first time that an analysis has been carried out of all the elements (soil, grain size, snow density, ice lenses and vegetation) that contribute to the microwave signal at three frequencies (36.5, 18.7 and $10.65 \mathrm{GHz}$ ) in a boreal forest. The study sheds light on DMRT-ML uncertainties related to small-scale variability and measurement errors in different environments and for different periods in the winter. Some limitations were raised on the accuracy of DMRT-ML to simulate the $T_{\mathrm{B}}$ of snowcovered surfaces, and this analysis will help to design fu- ture studies to improve the ability of DMRT-ML and other MSEM to model the radiative transfer processes of snowcovered surfaces.

Acknowledgements. The authors would like to thank the National Sciences and Engineering Research Council of Canada (NSERC) and Environment Canada for their financial support. The French collaboration was supported by the Programme de développement de partenariats stratégiques en matière d'enseignement et de recherche (FRQNT; Conseil franco-québécois de la coopération universitaire); the authors would like to thank Patrick Cliche, Serge Langlois, Nathalie Thériault, Caroline Dolant and Bruno-Charles Busseau (Université de Sherbrooke), Éric Lefebvre (Laboratoire de glaciologie et géophysique de l'environnement de Grenoble), Bernard Lesaffre (CNRM-GAME, MétéoFrance-CNRS) and Florent Dominé and Mathieu Barrère (Takuvik and Université Laval) for their contributions to the field work to obtain these measurements. Thanks as well to Peter Toose and Chris Derksen (Environment Canada) for providing part of Churchill data. The French polar institute (IPEV) has contributed through the BIPOL project. We also thank Élie Girard, Université de Sherbrooke, for his contributions in data processing and simulations. We would like to thank the two anonymous reviewers for their helpful comments.

Edited by: C. Duguay

\section{References}

Armstrong, R. L. and Brun, E.: Snow and climate: physical processes, in: Surface Energy Exchange and Modeling, Cambridge University Press, Cambridge, 222 pp., 2008.

Brucker, L., Picard, G., Arnaud, L., Barnola, J.-M., Schneebeli, M., Brunjail, H., Lefebvre, E., and Fily, M.: Modelling time series of microwave brightness temperature at Dome C, Antarctica, using vertically resolved snow temperature and microstructure measurements, J. Glaciol., 57, 171-182, 2011.

Champollion, N., Picard, G., Arnaud, L., Lefebvre, E., and Fily, M.: Hoar crystal development and disappearance at Dome C, Antarctica: observation by near-infrared photography and passive microwave satellite, The Cryosphere, 7, 1247-1262, doi:10.5194/tc-7-1247-2013, 2013.

Chang, A. T. C., Foster, J. L., and Hall, D. K.: Nimbus-7 SMMR derived global snow cover parameters, Ann. Glaciol., 9, 39-44, 1987.

Colbeck, S.: Theory of metamorphism of dry snow, J. Geophys. Res., 88, 5475-5482, 1983.

Courtemanche, B., Montpetit, B., Royer, A., and Roy, A.: Creation of a Lambertian microwave surface for retrieving the downwelling contribution in ground-based radiometric measurements, IEEE T. Geosci. Remote, 12, 462-466, 2015.

Derksen, C.: The contribution of AMSR-E 18.7 and $10.7 \mathrm{GHz}$ measurements to improved boreal forest snow water equivalent retrievals, Remote Sens. Environ., 112, 2701-2710, 2008.

Derksen, C., Toose, P., Lemmetyinen, J., Pulliainen, J., Langlois, A., Rutter, N., and Fuller, M.: Evaluation of passive microwave brightness temperature simulations and snow water 
equivalent retrievals through a winter season, Remote Sens. Environ., 117, 236-248, 2012.

Déry, S. J., Hernandez-Henriquez, M. A, Burford, J. E., and Wood, E. F.: Observational evidence of an intensifying hydrological cycle in the northern Canada, Geophys. Res. Lett., 36, L13402, doi:10.1029/2009GL038852, 2009.

Dierking, W., Linow, S., and Rack, W.: Toward a robust retrieval of snow accumulation over the Antarctic ice sheet using satellite radar, J. Geophys. Res., 117, D09110, doi:10.1029/2011JD017227, 2012.

Dupont, F., Picard, G., Royer, A., Fily, M., Roy, A., Langlois, A., and Champollion, N.: Modeling the microwave emission of bubbly ice: applications to blue ice and superimposed ice in the Antartic and Arctic, IEEE T. Geosci. Remote, 52, 6639-6651, 2014.

Durand, M., Kim, E. C., and Margulis, S.: Quantifying uncertainty in modeling snow microwave radiance for a mountain snowpack at the point-scale, including stratigraphic effects, IEEE T. Geosci. Remote, 46, 1753-1767, 2008.

Gallet, J.-C., Domine, F., Zender, C. S., and Picard, G.: Measurement of the specific surface area of snow using infrared reflectance in an integrating sphere at 1310 and $1550 \mathrm{~nm}$, The Cryosphere, 3, 167-182, doi:10.5194/tc-3-167-2009, 2009.

Goodison, B., Rubinstein, I., Thirkettle, F., and Langham, E.: Determination of snow water equivalent on the Canadian Prairies using microwave radiometry, Proc. of the Budapest Symposium, July 1986, Budapest, Hungary, 163-173, 1986.

Gouttevin, I., Menegoz, M., Dominé, F., Krinner, G., Koven, C., and Ciais, P.: How the insulating properties of snow affect soil carbon distribution in the continental pan-Arctic area, J. Geophys. Res., 117, G02020, doi:10.1029/2011JG001916, 2012.

Grenfell, T. C. and Warren, S. G.: Representation of a nonspherical ice particle by collection of independent spheres for scattering and absorption of radiation, J. Geophys. Res., 104, 3169731709, 1999.

Hancock, S., Baxter, R., Evans, J., and Huntley, B.: Evaluating global snow water equivalent products for testing land surface models, Remote Sens. Environ., 128, 107-117, 2013.

Heggli, M., Köchle, B., Matzl, M., Pinzer, B. R., Riche, F., Steiner, S., Steinfeld, D., and Schneebeli, M.: Measuring snow in 3-D using X-ray tomography: assessment of visualization techniques, Ann. Glaciol., 52, 231-236, 2011.

Jin, Y.: Electromagnetic Scattering Modelling for Quantitative Remote Sensing, World Scientific, Singapore, 1994.

Kohn, J. and Royer, A.: AMSR-E data inversion for soil temperature estimation under snow cover, Remote Sens. Environ., 114, 29512961, 2010.

Kokhanovsky, A. A. and Zege, E. P.: Scattering optics of snow, Appl. Optics, 43, 1589-1602, 2004.

Kontu, A. and Pulliainen, J.: Simulation of spaceborne microwave radiometer measurements of snow cover using in situ data and brightness temperature modeling, IEEE T. Geosci. Remote, 48, 1031-1044, 2010.

Kruopis, N., Praks, J., Arslan, A. N., Alasalmi, H. M., Koskinen, J. T., and Hallikainen, M. T.: Passive microwave measurements of snow-covered forest area in EMAC'95, IEEE T. Geosci. Remote, 37, 2699-2705, 1999.

Langlois, A.: Applications of the PR Series Radiometers for Cryospheric and Soil Moisture Research, Radiometrics Corporation, Colorado, 40 pp., 2015.
Latifovic, R., Zhu, Z.-L., Cihlar, J., Giri, C., and Olthof, I.: Land cover mapping of North and Central America - Global land cover 2000, Remote Sens. Envrion., 89, 116-127, 2004.

Lemmetyinen, J., Pulliainen, J., Rees, A., Kontu, A., Qiu, Y., and Derksen, C.: Multiple-layer adaptation of HUT snow emission model: comparison with experimental data, IEEE T. Geosci. Remote, 48, 2781-2794, 2010.

Lemmetyinen, J., Derksen, D., Toose, P., Proksh, M., Pulliainen, J., Kontu, A., Rautiainen, K., Seppänen, J., and Hallikainen, M.: Simulating seasonally and spatially varying snow cover brightness temperature using HUT snow emission model and retrieval of a microwave effective grain size, Remote Sens. Environ., 156, 71-95, 2015.

Lemmetyinen, J., Schwank, M., Rautiainen, K., Kontu, A., Parkkinen, T., Mätzler, C., Wiesmann, A., Wegmüller, U., Derksen, C., Toose, P., Roy, A., and Pulliainen, J.: Snow density and ground permittivity retrieved from L-Band radiometry: application to experimental data, Remote Sens. Environ., doi:10.1016/j.rse.2016.02.002, online first, 2016.

Liebe, H.: MPM - an atmospheric millimeter-wave propagation model, Int. J. Infrared. Milli., 10, 631-650, 1989.

Liston, G. E., McFadden, J. P., Sturm, M., and Pielke, R. A.: Modelled changes in arctic tundra snow, energy and moisture fluxes due to increased shrubs, Glob. Change Biol., 8, 17-32, 2002.

Löwe, H. and Picard, G.: Microwave scattering coefficient of snow in MEMLS and DMRT-ML revisited: the relevance of sticky hard spheres and tomography-based estimates of stickiness, The Cryosphere, 9, 2101-2117, doi:10.5194/tc-9-2101-2015, 2015.

Marsh, P. and Woo, M.-K.: Wetting front advance and freezing of meltwater within a snow cover 1 . observations in the Canadian arctic, Water Resour. Res., 20, 1853-1864, 1984.

Mätzler, C.: Applications of the interaction of microwaves with natural snow cover, Remote Sensing Reviews, 2, 259-392, 1987.

Mätzler, C.: Relation between grain-size and correlation length of snow, J. Glaciol., 48, 461-466, 2002.

Mesinger, F., Dimego, G., Kalnay, E., Mitchell, K., Shafran, P. C., Ebisuzaki, W., Jovic, D., Woollen, J., Rogers, E., Berbery, E. H., Ek, M. B., Fan, Y., Grumbine, R., Higgins, W., Li, H., Lin, Y., Manikin, G., Parrish, D., and Shi, W.: North American regional reanalysis, B. Am. Meteorol. Soc., 87, 343-360, 2006.

Montpetit, B.: Analyse de la modélisation de l'émission multifréquences micro-ondes et de la neige, incluant les croutes de glace à l'aide du modèle Microwave Emission Model of Layered Snowpack (MEMLS), PhD thesis, Université de Sherbrooke, Sherbrooke, 168 pp., available at: http://hdl.handle.net/11143/ 6844 (last access: 14 October 2015), 2015.

Montpetit, B., Royer, A., Langlois, A., Cliche, P., Roy, A., Champollion, N., Picard, G., Domine, F., and Obbard, R.: New shortwave infrared albedo measurements for snow specific surface area retrieval, J. Glaciol., 58, 941, doi:10.1016/j.coldregions.2010.01.004, 2012.

Montpetit, B., Royer, A., Roy, A., Langlois, L., and Derksen, D.: Snow microwave emission modeling of ice lenses within a snowpack using the microwave emission model for layered snowpacks, IEEE T. Geosci. Remote, 51, 4705-4717, doi:10.1109/TGRS.2013.2250509, 2013.

Picard, G., Brucker, L., Roy, A., Dupont, F., Fily, M., Royer, A., and Harlow, C.: Simulation of the microwave emission of multilayered snowpacks using the Dense Media Radiative transfer the- 
ory: the DMRT-ML model, Geosci. Model Dev., 6, 1061-1078, doi:10.5194/gmd-6-1061-2013, 2013.

Picard, G., Royer, A., Arnaud, L., and Fily, M.: Influence of meter-scale wind-formed features on the variability of the microwave brightness temperature around Dome C in Antarctica, The Cryosphere, 8, 1105-1119, doi:10.5194/tc-8-1105-2014, 2014.

Proksch, M., Löwe, H., and Schneebeli, M: Density, specific surface area, and correlation length of snow measured by highresolution penetrometry, J. Geophys. Res.-Earth, 120, 346-362, doi:10.1002/2014JF003266, 2015.

Pulliainen, J. T., Grandell, J., and Hallikainen, M. T.: HUT snow emission model and its applicability to snow water equivalent retrieval, IEEE T. Geosci. Remote, 37, 1378-1390, 1999.

Rees, A., Lemmetyinen, J., Derksen, C., Pulliainen, J. T., and English, M.: Observed and modelled effects of ice lens formation on passive microwave brightness temperatures over snow covered tundra, Remote Sens. Environ., 114, 116-126, 2010.

Rosenfeld, S. and Grody, N.: Anomalous microwave spectra of snow cover observed from special sensor microwave/imager measurements, J. Geophys. Res., 105, 14913-14925, 2000.

Roy, A., Royer, A., and Turcotte, R.: Improvement of springtime streamflow simulations in a boreal environment by incorporating snow-covered area derived from remote sensing data, J. Hydrol., 390, 35-44, 2010.

Roy, A., Royer, A., Wigneron, J.-P., Langlois, A., Bergeron, J., and Cliche, P.: A simple parameterization for a boreal forest radiative transfer model at microwave frequencies, Remote Sens. Environ., 124, 371-383, 2012.

Roy, A., Picard, G., Royer, A., Montpetit, B., Dupont, F., Langlois, A., Derksen, C., and Champollion, N.: Brightness temperature simulations of the Canadian seasonal snowpack driven by measurements of the snow specific surface area, IEEE T. Geosci. Remote, 51, 4692-4704, doi:10.1109/TGRS.2012.2235842, 2013.

Roy, A., Royer, A., and Hall, J. R.: Relationship between forest microwave transmissivity and structural parameters for the Canadian boreal forest, Geophys. Res. Lett., 11, 1802-1806, 2014.
Roy, A., Royer, A., Montpetit, B., and Langlois, A.: Microwave snow emission modeling of boreal forest environments, Proc. IGARSS2015, 26-31 July 2015, Milan, Italy, 1-4, 2015.

Rutter, N., Sandells, M., Derksen, C., Toose, P., Royer, A., Montpetit, B., Langlois, A., Lemmetyinen, J., and Pulliainen, J.: Snow stratigraphic heterogeneity within groundbased passive microwave radiometer footprints: implications for emission modeling, J. Geophys. Res. Earth, 119, 550-565, doi:10.1002/2013JF003017, 2013.

Schneebeli, M., Pielmeier, C., and Johnson, J.: Measuring snow microstructure and hardness using a high resolution penetrometer, Cold Reg. Sci. Technol., 30, 101-114, doi:10.1016/S0165232X(99)00030-0, 1999.

Schuur, E. A. G., Abbott, B. W., Bowden, W. B., Brovkin, V., Camill, P., and Canadell, J. G.: Expert assessment of vulnerability of permafrost carbon to climate change, Climatic Change, 119, 359-374, 2013.

Takala, M., Luojus, K., Pulliainen, J., Derksen, C., Lemmetyinen, J., Kärnä, J.-P., and Koskinen, J.: Estimating Northern Hemisphere snow water equivalent for climate research through assimilation of space-borne radiometer data and ground-based measurements, Remote Sens. Environ., 115, 3517-3529, 2011.

Tedesco, M. and Kim, E. J.: Intercomparison of electromagnetic models for passive microwave remote sensing of snow, IEEE T. Geosci. Remote, 44, 2654-2666, 2006.

Tsang, L., Kong, J. A., Ding, K.-H., and Ao, C. O.: Scattering of Electromagnetic Waves: Numerical Simulations, Wiley, New York, NY, USA, 2001.

Tsang, L., Liang, D., Xu, X., and Xu, P.: Microwave emission from snowpacks: modeling the effects of volume scattering, surface scattering and layering, in: Proc. 10th Spec. Meet. Microw. Radiometry Remote Sens. Environ. (MicroRad), 11-14 March 2008, Firenze, Italy, 1-4 pp., 2008.

Wegmüller, U. and Mätzler, C.: Rough bare soil reflectivity model, IEEE T. Geosci. Remote, 37, 1391-1395, 1999.

Wiesmann, A., Mätzler, C., and Weise, T.: Radiometric and structural measurements of snow samples, Radio Sci., 33, 273-289, 1998. 